\title{
Enrichment of Mesophilic and Thermophilic Mixed Microbial Consortia for Syngas Biomethanation: The Role of Kinetic and Thermodynamic Competition
}

\author{
Grimalt_Alemany, Antonio ; yk, Mateusz; Kennes-Veiga, David M.; Skiadas, loannis V; Gavala, Hariklia N.
}

Published in:

Waste and Biomass Valorization

Link to article, DOI:

$10.1007 / \mathrm{s} 12649-019-00595-z$

Publication date:

2020

Document Version

Peer reviewed version

Link back to DTU Orbit

Citation (APA):

Grimalt Alemany, A., yk, M., Kennes-Veiga, D. M., Skiadas, I. V., \& Gavala, H. N. (2020). Enrichment of Mesophilic and Thermophilic Mixed Microbial Consortia for Syngas Biomethanation: The Role of Kinetic and Thermodynamic Competition. Waste and Biomass Valorization, 11, 465-481. https://doi.org/10.1007/s12649019-00595-z

\section{General rights}

Copyright and moral rights for the publications made accessible in the public portal are retained by the authors and/or other copyright owners and it is a condition of accessing publications that users recognise and abide by the legal requirements associated with these rights.

- Users may download and print one copy of any publication from the public portal for the purpose of private study or research.

- You may not further distribute the material or use it for any profit-making activity or commercial gain

- You may freely distribute the URL identifying the publication in the public portal 


\title{
1 Enrichment of mesophilic and thermophilic mixed microbial consortia 2 for syngas biomethanation: the role of kinetic and thermodynamic 3 competition
}

4

\author{
Antonio Grimalt-Alemany ${ }^{1}$, Mateusz Lężyk ${ }^{1,2}$, David M. Kennes-Veiga ${ }^{1}$, Ioannis V. Skiadas ${ }^{1}$ and Hariklia N. \\ Gavala $^{1 *}$ \\ *Correspondence: hnga@kt.dtu.dk, hari_gavala@yahoo.com \\ ${ }^{1}$ Department of Chemical and Biochemical Engineering, Technical University of Denmark, Søltofts Plads 229, 2800 \\ Kgs. Lyngby, Denmark. \\ ${ }^{2}$ Current address: Institute of Environmental Engineering, Faculty of Civil and Environmental Engineering, Poznan \\ University of Technology, Berdychowo 4, 60-965 Poznań, Poland.
}

\begin{abstract}
Mixed culture-based syngas biomethanation is a robust bioconversion process with high versatility in terms of exploitable feedstocks and potential applications, as it could be operated independently, or coupled to anaerobic digestion systems and in-situ biogas upgrading processes. Typically, the syngas biomethanation consists in the stepwise conversion of syngas into methane through a number of catabolic routes, which may vary considerably depending on the operating conditions. In this study, two enrichments were performed at $37^{\circ} \mathrm{C}$ and $60^{\circ} \mathrm{C}$ to investigate the effect of the incubation temperature on the microbial selection process and the dominant catabolic routes followed. This was carried out through the characterization of the catabolic routes and the microbial composition of the enriched cultures, and a thermodynamic feasibility study on their metabolic networks. The enrichments resulted in two stable microbial consortia with different patterns of activity. The mesophilic enriched consortium presented a more intricate metabolic network composed by four microbial trophic groups, where aceticlastic methanogenesis contributed to $64.9 \pm 8.3 \%$ of the $\mathrm{CH}_{4}$ production. The metabolic network of the thermophilic enriched consortium was much simpler, consisting in the syntrophic association of carboxydotrophic hydrogenogens and hydrogenotrophic methanogens. This led to significant differences in methane productivity, corresponding to $1.83 \pm 0.27$ and $33.48 \pm 0.90 \mathrm{mmol} \mathrm{CH}_{4} / \mathrm{g} \mathrm{VSS} / \mathrm{h}$ for the mesophilic and the thermophilic enriched consortium, respectively, which would potentially make the thermophilic consortium more suited for industrial applications. 16S rRNA gene amplicon analysis indicated the presence of strains with similarity to Acetobacterium sp., Methanospirillum hungateii, Methanospirillum stamsii and Methanothrix sp. at mesophilic conditions, and Thermincola carboxydiphila and Methanothermobacter sp. at thermophilic conditions, implying a role in the conversion of syngas. The thermodynamic feasibility study demonstrated that the microbial selection was not driven solely by kinetic competition, since thermodynamic limitations also played a significant role defining the dominant catabolic routes.
\end{abstract}




\section{Statement of novelty}

2 In this study, stable mesophilic and thermophilic enriched microbial consortia able to fully convert syngas into $\mathrm{CH}_{4}$ were 3 developed. The enrichments had a strong effect on the catabolic routes dominating the conversion of syngas. Furthermore, 4 the thermodynamic analysis of the metabolic network of the enriched consortia demonstrated that the microbial selection 5 through the enrichments was not solely dictated by the kinetics of the microbial community, since the thermodynamic 6 limitation of several biochemical reactions also played an important role defining the activity of the enriched consortia. The 7 findings show that analyzing the thermodynamics and applying thermodynamic control over the metabolic routes followed 8 in the bioconversion can contribute significantly to optimizing the operational conditions favoring high productivities in 9 mixed-culture based industrial processes.

\section{Keywords}

11 Syngas, carbon monoxide, hydrogen, methane, mixed cultures, thermodynamics

\section{Introduction}

The increasing energy demands along with the need of replacing fossil resources have motivated a paradigm shift towards sustainable production of commodity chemicals and biofuels. One of such chemicals with a high versatility in terms of potential applications is biomethane, as it can be used either for heat and power generation, direct injection into the gas grid or as a transportation fuel [1]. Additionally, recent findings point at methane as a potential platform chemical to biosynthesize a number of high added value products such as single cell protein, polyhydroxyalkanoates and extracellular polysaccharides [2].

The production of biomethane can take place through several conversion routes and from a wide variety of feedstocks. The conventional process for biomethane (or biogas) production is the anaerobic digestion process, which has long been applied for the treatment of wastewater and different types of organic wastes from the agricultural sector [3, 4]. However, when it comes to recalcitrant biomasses, the anaerobic digestion process typically suffers from low conversion efficiencies due to the presence of refractory biomass fractions [5]. One of the alternatives to overcome the low biodegradability of recalcitrant biomasses is the gasification of either the solid effluent fraction from anaerobic digesters or the whole biomass into synthesis gas, a mixture of primarily $\mathrm{H}_{2}, \mathrm{CO}$ and $\mathrm{CO}_{2}$, which can be further converted biologically into methane through the syngas biomethanation process. Both gasification and syngas biomethanation present a number of inherent merits. On one hand, applying thermochemical conversion methods provides higher conversion efficiency and broadens the range of exploitable feedstocks as any type of biomass can be gasified regardless of recalcitrance or toxicity, including nonfermentable by-products and biomass fractions, forestry residues and municipal solid wastes [6]. On the other hand, the biomethanation of synthesis gas constitutes a multi-purpose process as it can be used for converting biomass-derived syngas and $\mathrm{CO} / \mathrm{CO}_{2}$-rich off-gas streams from several industrial processes into methane and carbon dioxide [7], or as an in-situ biogas upgrading technology by addition of an external $\mathrm{H}_{2}$ supply to the biomethanation unit [8]. Therefore, the syngas 
1 biomethanation process holds a significant application potential either as a stand-alone technology or integrated in current anaerobic digestion systems for improving the biomass conversion efficiency and the methane content of the gaseous outlet.

The anaerobic microbial conversion of synthesis gas into $\mathrm{CH}_{4}$ supports growth of a variety of microbial trophic groups and can take place through different catabolic routes. Direct conversion of $\mathrm{H}_{2} / \mathrm{CO}_{2}$ into $\mathrm{CH}_{4}$ by hydrogenotrophic methanogens is widespread among methanogenic archaea and has been well studied. On the other hand, direct conversion of $\mathrm{CO}$ into $\mathrm{CH}_{4}$ is rare and, so far, only a few species have been found to be capable of carboxydotrophic methanogenesis, with all of them presenting rather long doubling times [9-12]. When using open mixed microbial consortia though, the direct biomethanation of $\mathrm{CO}$ has never been reported as carboxydotrophic methanogens are generally inhibited by relatively low partial pressures of $\mathrm{CO}\left(\mathrm{P}_{\mathrm{CO}}\right)$ and are easily outcompeted by other faster-growing carboxydotrophic microbial groups such as carboxydotrophic acetogens or hydrogenogens [13-15]. As a result, the biomethanation of syngas typically requires the syntrophic association of several microbial trophic groups and comprises a rather complex network of biochemical reactions mainly including the biological water-gas shift reaction, carboxydotrophic acetogenesis, homoacetogenesis, hydrogenotrophic methanogenesis and acetoclastic methanogenesis [1]. However, the dominance of each of the catabolic routes has been shown to shift depending on the operating conditions applied. Navarro et al. [13] studied the effect of the $\mathrm{P}_{\mathrm{CO}}$ using a mesophilic granular sludge and found that aceticlastic methanogenesis was dominant at $\mathrm{P}_{\mathrm{CO}}$ below $0.5 \mathrm{~atm}$, while the carbon flux shifted towards syntrophic acetate oxidation and hydrogenotrophic methanogenesis when increasing the $\mathrm{P}_{\mathrm{CO}}$ to $1 \mathrm{~atm}$. Similar observations were made when studying the effect of the incubation temperature as carboxydotrophic acetogenesis was found to be gradually replaced by carboxydotrophic hydrogenogenesis when increasing the incubation temperature from $45^{\circ} \mathrm{C}$ onwards, which consequently changed the dominant catabolic routes leading to methane [14]. This illustrates the dynamic nature of microbial communities, which respond rapidly to changes in environmental conditions by adjusting the structure of their microbial population towards the most efficient catabolic routes.

Studying changes in the microbial community structure and activity when exposed to different operating conditions is thus fundamental for understanding the population dynamics determining the outcome of microbial conversion processes. The evolution of the activity and composition of syngas-converting methanogenic microbial communities upon exposure to syngas as the sole carbon and energy source using mesophilic and thermophilic anaerobic sludges has been recently studied through microbial enrichments in batch mode $[15,16]$. However, both of these enrichment studies resulted in the development of enriched cultures with limited methanogenic potential, as significant amounts of acetate remained unconverted in the fermentation broth due to the absence of certain methanogenic microbial groups in the mixed cultures. Thus, this work focuses on the development of both mesophilic and thermophilic syngas-converting methanogenic enriched cultures with high product selectivity towards $\mathrm{CH}_{4}$. The goal of this study is to characterize the syngas conversion routes utilized by open mixed microbial consortia enriched at different temperatures as well as to assess the role of kinetic and thermodynamic competition in defining the microbial interactions present in each enriched consortium as a result of the microbial selection process. This is carried out by analyzing the catabolic routes employed by the enriched consortia through specific activity tests, determining their microbial composition based on 16S rRNA gene amplicon sequencing, and studying the thermodynamics of their metabolic networks. 


\section{Materials and methods}

\subsection{Growth medium}

The growth medium used in all experiments corresponded to a modified basal anaerobic (BA) medium composed by 7 stock solutions. The composition of the stock solutions was the following: salts solution $\left(\mathrm{NH}_{4} \mathrm{Cl}, 100 \mathrm{~g} / \mathrm{l} ; \mathrm{NaCl}, 10 \mathrm{~g} / \mathrm{l}\right.$; $\mathrm{MgCl}_{2} \cdot 6 \mathrm{H}_{2} \mathrm{O}, 10 \mathrm{~g} / \mathrm{l} ; \mathrm{CaCl}_{2} \cdot 2 \mathrm{H}_{2} \mathrm{O}, 5 \mathrm{~g} / \mathrm{l}$ ), vitamins solution (biotin, $2 \mathrm{mg} / \mathrm{l}$; folic acid, $2 \mathrm{mg} / \mathrm{l}$; pyridoxine-HCl, $10 \mathrm{mg} / \mathrm{l}$; riboflavin- $\mathrm{HCl}, 5 \mathrm{mg} / \mathrm{l}$; thiamine- $\mathrm{HCl}, 5 \mathrm{mg} / \mathrm{l}$; cyanocobalamine, $0.1 \mathrm{mg} / \mathrm{l}$; nicotinic acid, $5 \mathrm{mg} / \mathrm{l}$; p-aminobenzoic acid, 5 $\mathrm{mg} / \mathrm{l}$; lipoic acid, $5 \mathrm{mg} / \mathrm{l}$; D-pantothenic acid hemicalcium salt, $5 \mathrm{mg} / \mathrm{l})$, trace metal solution $\left(\mathrm{FeCl}_{2} \cdot 4 \mathrm{H}_{2} \mathrm{O}, 2000 \mathrm{mg} / \mathrm{l}\right.$; $\mathrm{H}_{3} \mathrm{BO}_{3}, 50 \mathrm{mg} / \mathrm{l} ; \mathrm{ZnCl}_{2}, 50 \mathrm{mg} / \mathrm{l} ; \mathrm{CuCl}_{2}, 30 \mathrm{mg} / \mathrm{l} ; \mathrm{MnCl}_{2} \cdot 4 \mathrm{H}_{2} \mathrm{O}, 50 \mathrm{mg} / \mathrm{l} ;\left(\mathrm{NH}_{4}\right)_{6} \mathrm{Mo}_{7} \mathrm{O}_{24} \cdot 4 \mathrm{H}_{2} \mathrm{O}, 50 \mathrm{mg} / \mathrm{l} ; \mathrm{AlCl}_{3}, 50 \mathrm{mg} / \mathrm{l}$; $\left.\mathrm{CoCl}_{2} \cdot 6 \mathrm{H}_{2} \mathrm{O}, 50 \mathrm{mg} / \mathrm{l} ; \mathrm{NiCl}_{2}, 50 \mathrm{mg} / \mathrm{l} ; \mathrm{Na}_{2} \mathrm{SeO}_{3} \cdot 5 \mathrm{H}_{2} \mathrm{O}, 100 \mathrm{mg} / \mathrm{l} ; \mathrm{Na}_{2} \mathrm{WO}_{4} \cdot 2 \mathrm{H}_{2} \mathrm{O}, 60 \mathrm{mg} / \mathrm{l}\right)$, sodium bicarbonate solution $\left(\mathrm{NaHCO}_{3}, 52 \mathrm{~g} / \mathrm{l}\right)$, potassium phosphate dibasic solution $\left(\mathrm{K}_{2} \mathrm{HPO}_{3}, 152 \mathrm{~g} / \mathrm{l}\right)$, chelating agent solution (Nitrilotriacetic acid, 1 $\mathrm{g} / \mathrm{l})$ and reducing agent solution $\left(\mathrm{Na}_{2} \mathrm{~S} \cdot 9 \mathrm{H}_{2} \mathrm{O}, 25 \mathrm{~g} / \mathrm{l}\right)$. The medium was prepared by adding $10 \mathrm{ml} / \mathrm{l}$ of salts solution, $10 \mathrm{ml} / \mathrm{l}$ of vitamins solution, $1 \mathrm{ml} / 1$ of trace metal solution, $50 \mathrm{ml} / 1$ of sodium bicarbonate solution, $2 \mathrm{ml} / 1$ of potassium phosphate dibasic solution, $20 \mathrm{ml} / 1$ of chelating agent solution, $10 \mathrm{ml} / 1$ of reducing agent solution (added after sealing the flasks under anaerobic conditions) and distilled water up to $1 \mathrm{~L}$.

\subsection{Inoculum and microbial enrichment experiments}

A mixture of two different types of anaerobic sludge was used as inoculum for mesophilic and a thermophilic microbial enrichment. The two anaerobic sludges used were collected from the Lundtofte Wastewater Treatment plant (Denmark) and from a lab-scale anaerobic digester fed solely with manure (at Chemical and Biochemical Engineering Department, Technical University of Denmark). Prior to inoculation, the anaerobic sludges were mixed in equal amounts ( $1 / 1 \mathrm{v} / \mathrm{v})$ while flushing with $\mathrm{N}_{2}$ to ensure anaerobic conditions. The Total Suspended Solids concentration (TSS) and the Volatile Suspended Solids concentration (VSS) of the mixture of anaerobic sludges corresponded to $25.4 \pm 0.1 \mathrm{~g}$ TSS/l and $15.3 \pm 0.2$ g VSS/l, respectively.

A batch enrichment technique was used in the mesophilic and the thermophilic enrichment series, which consisted in the successive transfer of the active enrichment cultures into flasks with fresh medium and synthetic syngas mixture $\left(\mathrm{H}_{2}, \mathrm{CO}\right.$ and $\mathrm{CO}_{2}$ ). Both enrichments comprised a total of 5 transfers using a constant initial partial pressure of gases and an inoculum size of $15 \% \mathrm{v} / \mathrm{v}$. The enrichments were performed in duplicates, using the individual experiment with the highest $\mathrm{CH}_{4}$ yield as inoculum for the next set of duplicates. The two series of enrichment experiments were performed in $330 \mathrm{ml}$ flasks with an active volume of $100 \mathrm{ml}$. A volume of $85 \mathrm{ml}$ of medium was first added to the flasks, flushed with $\mathrm{H}_{2}$ to ensure anaerobic conditions and sealed with rubber stoppers and screw plugs. After sealing the flasks, additional $\mathrm{H}_{2}, \mathrm{CO}$ and $\mathrm{CO}_{2}$ were added to the flasks anaerobically up to a final partial pressure after inoculation of $1.3 \mathrm{~atm}\left(\mathrm{P}_{\mathrm{H} 2}\right), 0.4 \mathrm{~atm}\left(\mathrm{P}_{\mathrm{CO}}\right)$ and $0.3 \mathrm{~atm}\left(\mathrm{P}_{\mathrm{CO} 2}\right)$ at $25{ }^{\circ} \mathrm{C}$ using a precision pressure indicator (model CPH6400, WIKA, Germany). The final $\mathrm{P}_{\mathrm{CO} 2}$ decreased to approximately $0.2 \mathrm{~atm}$ due to solubilization in the medium. The incubation temperature corresponded to $37{ }^{\circ} \mathrm{C}$ for the mesophilic enrichment and $60{ }^{\circ} \mathrm{C}$ for the thermophilic enrichment. All flasks were incubated in a rotary shaker incubator at $100 \mathrm{rpm}$. The average initial $\mathrm{pH}$ of the enrichment after inoculation was $6.99 \pm 0.16$ at mesophilic conditions and 
$7.08 \pm 0.14$ at thermophilic conditions. A bicarbonate buffer was used to prevent significant changes in the $\mathrm{pH}$ during the fermentations. Mesophilic and thermophilic control experiments with no addition of syngas to evaluate the contribution of the organic matter from the inoculum to the overall product recovery were incubated at the same conditions with a headspace composition of $1.7 \mathrm{~atm}$ of $\mathrm{N}_{2}$ and $0.3 \mathrm{~atm}$ of $\mathrm{CO}_{2}\left(0.2 \mathrm{~atm}\right.$ final $\left.\mathrm{P}_{\mathrm{CO} 2}\right)$. The headspace composition of the transfer.

\subsection{Identification of catabolic routes}

The analysis of the catabolic routes employed by the mesophilic and the thermophilic enriched microbial consortia was carried out by combining specific activity tests with either $\mathrm{CO}, \mathrm{H}_{2} / \mathrm{CO}_{2}$ or acetate as the only substrate and the use of sodium 2-bromoethanesulfonate (BES) $(15 \mathrm{mM})$ for inhibiting methanogenic archaea and allowing the identification of intermediate products used by each enriched microbial consortium. The initial experimental conditions used for each experiment, including initial partial pressure of gases, acetate concentration and addition of BES, are summarized in table 1. All experiments were carried out in triplicates in $330 \mathrm{ml}$ flasks using an active volume of $100 \mathrm{ml}$ and an inoculum size of $20 \% \mathrm{v} / \mathrm{v}$, which corresponded to an initial VSS concentration of $23.7 \pm 2.5 \mathrm{mg}$ VSS/1 for the mesophilic enrichment culture

Table 1. Initial partial pressure of gases, concentration of acetate and BES concentration used in the specific activity tests performed at mesophilic and thermophilic conditions.

\begin{tabular}{lcccccc}
\hline & $\mathrm{H}_{2}(\mathrm{~atm})$ & $\mathrm{CO}(\mathrm{atm})$ & $\mathrm{CO}_{2}(\mathrm{~atm})$ & $\mathrm{N}_{2}(\mathrm{~atm})$ & $\begin{array}{c}\mathrm{NaCH}_{3} \mathrm{COO} \\
(\mathrm{mM})\end{array}$ & BES (mM) \\
\hline $\mathrm{CO}+\mathrm{BES}$ & - & 0.4 & 0.2 & 1.4 & - & 15 \\
$\mathrm{H}_{2} / \mathrm{CO}_{2}+\mathrm{BES}$ & 0.8 & - & 0.2 & 1 & - & 15 \\
$\mathrm{H}_{2} / \mathrm{CO}_{2}$ & 0.8 & - & 0.2 & 1 & - & - \\
Acetate & - & - & 0.2 & 1.8 & 25 & - \\
$\mathrm{H}_{2} / \mathrm{CO}_{2}+\mathrm{CO}$ & 1.0 & 0.4 & 0.2 & 0.4 & - & - \\
\hline
\end{tabular}




\subsection{Analytical methods}

2 The composition of the headspace $\left(\mathrm{H}_{2}, \mathrm{CO}, \mathrm{CO}_{2}\right.$ and $\left.\mathrm{CH}_{4}\right)$ was analyzed using a gas chromatograph (model 8610C, SRI 3 Instruments, USA) with a thermal conductivity detector and two packed columns, a Molsieve 13X column (6' x 1/8") and a silica gel column (6' x 1/8") connected in series with a rotating valve. The column temperature conditions were: $65^{\circ} \mathrm{C}$ for 3 min, temperature ramp of $10^{\circ} \mathrm{C} / \mathrm{min}$ up to $95^{\circ} \mathrm{C}$ and a second ramp of $24^{\circ} \mathrm{C} / \mathrm{min}$ from $95^{\circ} \mathrm{C}$ to $140^{\circ} \mathrm{C}$. Liquid samples were analyzed for volatile fatty acids (VFA) and alcohols using a High Performance Liquid Chromatograph (Shimadzu, USA) equipped with a refractive index detector and an Aminex HPX-87H column (Bio-Rad, USA) at $63^{\circ} \mathrm{C}$. The flow rate of the eluent (12 mM H $\mathrm{H}_{2} \mathrm{SO}_{4}$ solution) corresponded to $0.6 \mathrm{ml} / \mathrm{min}$. Microbial biomass growth was monitored based on the absorbance of liquid samples (600 nm) using a spectrophotometer (DR2800, Hach Lange). The absorbance of the liquid samples was correlated to the concentration of Volatile Suspended Solids (VSS) determined according to standard methods for each of the enriched microbial consortia [17].

\subsection{DNA isolation and amplicon sequencing}

Samples for extraction of total genomic DNA were collected at the late exponential phase (day 4) of fermentations performed in triplicates, corresponding to transfer T7 of the mesophilic and the thermophilic microbial enrichments. Total manufacturer recommendations. DNA samples were submitted to Macrogen Inc. (Korea) for 16S rRNA amplicon library preparation and sequencing using Illumina Miseq instrument (300bp paired-end sequencing). Libraries were prepared according to 16S Metagenomic Sequencing Library Preparation Protocol (Illumina, Part \#15044223, Rev. B), with Herculase II Fusion DNA Polymerase Nextera XT Index Kit V2. Amplification of V3 and V4 region of $16 \mathrm{~S}$ rRNA gene was carried out with Pro341F (5'-CCTACGGGNBGCASCAG-3') and Pro805R (5'-GACTACNVGGGTATCTAATCC-3') from Takahashi et al. [18], while amplification of V4 and V5 region was performed with 515FB (5'GTGYCAGCMGCCGCGGTAA-3') and 926R (5'-CCGYCAATTYMTTTRAGTTT-3') from Walters et al. [19].

\subsection{Analysis of $16 \mathrm{~S}$ rRNA gene amplicons}

Remaining read-through adapters were clipped using cutadapt [20]. Subsequently, paired reads were merged using usearchfastq_mergepairs, allowing for $80 \%$ identity and up to 10 mismatches in the alignment. Only merged reads containing primer sequences were kept and primer sequences were stripped for subsequent analysis. Subsequently, filtering, generation of Operational Taxonomic Units (OTUs) and mapping of reads to OTUs was performed using the UPARSE/unoise3 pipeline [21]. In brief, reads were quality filtered using usearch-fastq_filter and maximum expected error threshold to 1.0 and uniques identified using usearch-fastx_uniques. Only reads with abundance more than 8 were kept. These were denoised and chimera-filtered using UNOISE3 [21]. Taxonomy names were assigned to OTUs using SINTAX [22] and SILVA v132 LTP database of 13899 curated 16S sequences using 0.8 bootstrap confidence threshold [23]. To create OTU table, unfiltered reads were mapped to OTUs using usearch-otutab. Sample data from replicate runs were collapsed based on the median count and each sample was normalized to the depth of the sample with least-mapped counts. Downstream analyses were performed with Qiime and STAMP [24]. 


\subsection{Thermodynamic feasibility}

2 The thermodynamics of the metabolic network was evaluated based on the Gibbs free energy change $\left(\Delta_{\mathrm{r}} \mathrm{G}^{\circ}\right)$ of the overall biochemical reactions present in each of the enriched microbial consortia. Standard Gibbs free energies of formation $\left(\Delta_{\mathrm{f}} \mathrm{G}^{\circ}\right)$ and standard enthalpies of formation $\left(\Delta_{\mathrm{f}} \mathrm{H}^{\circ}\right)$ used were obtained from Alberty [25] and Amend and Shock [26]. The $\Delta_{\mathrm{f}} \mathrm{G}^{\circ}$ were first corrected for temperature and ionic strength according to the Gibbs-Helmholtz equation (eq. 1) and the extended Debye-Hückel equation (eq. 2) [25].

$$
\Delta_{f} G_{i}^{\prime}(T)=\Delta_{f} G^{\circ}{ }_{i}(298.15 K) \cdot \frac{T}{298.15 K}+\Delta_{f} H^{\circ}{ }_{i}(298.15 K) \cdot \frac{298.15 K-T}{298.15 K}
$$

$$
\Delta_{f} G_{i}^{\circ}(I)=\Delta_{f} G_{i}^{\circ}(I=0)-\frac{R T A z_{i}^{2} I^{1 / 2}}{1+B I^{1 / 2}}
$$

where $\mathrm{z}_{\mathrm{i}}$ is the charge number of compound $i, \mathrm{I}$ is the ionic strength of the medium, A was calculated as a function of temperature according to Alberty [25] and $\mathrm{B}$ is an empirical constant that takes a value of $1.6 \mathrm{~L}^{1 / 2} \mathrm{~mol}^{-1 / 2}$ within a range of ionic strength of 0.05-0.25 M [25]. Subsequently, the Gibbs free energy change of the reactions considered $\left(\Delta_{\mathrm{r}} \mathrm{G}_{\mathrm{T}}^{\prime}\right)$ was corrected for the actual partial pressure of gases and concentration of metabolites according to equation 3 , and the effect of the $\mathrm{pH}$ was corrected as described in Steinbusch et al. [27].

$$
\Delta_{r} G_{T}^{\prime}=\Delta_{r} G_{T}^{\circ}(I=0.08 M)+R T \ln \frac{[C]^{c}[D]^{d}}{[A]^{a}[B]^{b}}
$$

The thermodynamic potential factor $\left(\mathrm{F}_{\mathrm{T}}\right)$, calculated according to equation 4 , was introduced by Jin \& Bethke [28] to include thermodynamic consistency in kinetic models (e.g. $\left.\mu=\mu_{\max } \cdot S /\left(k_{s}+S\right) \cdot F_{T}\right)$ by considering the energy released and the energy conserved through a specific metabolic pathway. However, in this study, $\mathrm{F}_{\mathrm{T}}$ calculations were used to identify possible bioenergetic limitations affecting the rate of conversion of the biochemical reactions composing the metabolic network of the enriched consortia under the operating conditions found experimentally, as described in Grimalt-Alemany et al. [29], and to determine the minimum threshold concentration of substrate for each microbial group considered. The $\mathrm{F}_{\mathrm{T}}$ was calculated according to equation 4 and 5 .

$$
\begin{gathered}
F_{T}=1-\exp \left(-\frac{\Delta G_{A}-\Delta G_{C}}{\chi R T}\right) \\
\Delta G_{C}=Y_{A T P} \cdot \Delta G_{p}
\end{gathered}
$$

where $\Delta \mathrm{G}_{\mathrm{A}}$ equals to $-\Delta_{\mathrm{r}} \mathrm{G}_{\mathrm{T}}^{\prime}$ in $\mathrm{kJ}$ per reaction; $\Delta \mathrm{G}_{\mathrm{C}}$ is the energy conserved calculated based on the ATP yield of each metabolic pathway multiplied by the Gibbs free energy of phosphorylation $\left(\Delta \mathrm{G}_{\mathrm{p}}\right)$; and $\chi$ is the average stoichiometric number, which can be approximated by the number of times a rate-determining step takes place through a metabolic pathway. When $\Delta \mathrm{G}_{\mathrm{A}}>\Delta \mathrm{G}_{\mathrm{C}}, \mathrm{F}_{\mathrm{T}}$ approaches 1 , which indicates that there is a strong thermodynamic driving force for a specific reaction to proceed forward, and thus the rate of the reaction is strictly dependent on the kinetic properties of the microbial species in question. When $\Delta \mathrm{G}_{\mathrm{A}} \approx \Delta \mathrm{G}_{\mathrm{C}}, \mathrm{F}_{\mathrm{T}}$ approaches 0 , the thermodynamic drive is low and $\mathrm{F}_{\mathrm{T}}$ has a strong 
1 effect on the reaction rate, indicating that the reaction rate is thermodynamically controlled. When $\Delta \mathrm{G}_{\mathrm{A}}$ is equal to or lower than $\Delta \mathrm{G}_{\mathrm{C}}, \mathrm{F}_{\mathrm{T}}$ is 0 or negative, respectively, and the thermodynamic drive for the reaction to proceed forward disappears and the metabolism stops.

$\mathrm{F}_{\mathrm{T}}$ calculations for acetogenic growth on $\mathrm{H}_{2} / \mathrm{CO}_{2}$ and $\mathrm{CO}$ were performed using an ATP yield of $0.33 \mathrm{~mol} \mathrm{ATP} / \mathrm{mol}$ acetate and $1.66 \mathrm{~mol} \mathrm{ATP} / \mathrm{mol}$ acetate, respectively, calculated using the $\mathrm{H}^{+} / \mathrm{Na}^{+}$translocation described in Bertsch \& Müller [30] for Acetobacterium woodii and an ATP synthesis stoichiometry of $3 \mathrm{H}^{+} / \mathrm{Na}^{+}$per ATP formed. The reverse reaction for syntrophic acetate oxidation and the syntrophic propionate oxidation reaction were assumed to have an ATP yield of 0.33 mol ATP/mol acetate or propionate [31]. The hydrogenogenesis was assumed to translocate one $\mathrm{H}^{+}$across the membrane per mol of CO through an energy-conserving hydrogenase, which would result in an ATP yield of $0.33 \mathrm{~mol} \mathrm{ATP} / \mathrm{mol} \mathrm{CO}$ using an ATP synthesis stoichiometry of $3 \mathrm{H}^{+}$per ATP synthesized. Lastly, both aceticlastic and hydrogenotrophic methanogenesis were assumed to be performed by species without cytochromes with an ATP yield of $0.5 \mathrm{~mol} \mathrm{ATP} / \mathrm{mol}$ $\mathrm{CH}_{4}$ resulting from the translocation of $6 \mathrm{Na}^{+}\left(1 \mathrm{~mol}\right.$ ATP invested in acetate activation) and $2 \mathrm{Na}^{+}$across the membrane, respectively, and using an ATP synthesis stoichiometry of $4 \mathrm{Na}^{+}$per ATP formed [32]. The rate-determining step for hydrogenotrophic and aceticlastic methanogenesis was assumed to be the translocation of $\mathrm{Na}^{+}$by the methyl transferase complex (Mtr). The ATP yields and $\chi$ used for $\mathrm{F}_{\mathrm{T}}$ calculations are summarized in table 2. To account for uncertainties in the ATP yields used, three different values of $\Delta \mathrm{G}_{\mathrm{p}}$ covering a rather broad range were considered in $\mathrm{F}_{\mathrm{T}}$ calculations, corresponding to $45 \mathrm{~kJ} / \mathrm{mol}$ ATP, $50 \mathrm{~kJ} / \mathrm{mol}$ ATP and $55 \mathrm{~kJ} / \mathrm{mol}$ ATP.

Table 2. Overall biochemical reactions, ATP yield and average stoichiometric number used in thermodynamic potential factor $\left(\mathrm{F}_{\mathrm{T}}\right)$ calculations.

\begin{tabular}{|c|c|c|c|}
\hline Stoichiometry of biochemical reactions & $\begin{array}{c}\text { ATP yield } \\
(\text { mol per reaction })\end{array}$ & $\chi$ & Ref. \\
\hline \multicolumn{4}{|l|}{ Acetogenesis } \\
\hline $4 \mathrm{H}_{2}+2 \mathrm{CO}_{2} \rightarrow \mathrm{CH}_{3} \mathrm{COOH}+2 \mathrm{H}_{2} \mathrm{O}$ & 0.33 & 1 & [30] \\
\hline $4 \mathrm{CO}+2 \mathrm{H}_{2} \mathrm{O} \rightarrow \mathrm{CH}_{3} \mathrm{COOH}+2 \mathrm{CO}_{2}$ & 1.66 & 5 & [30] \\
\hline \multicolumn{4}{|l|}{ Hydrogenogenesis } \\
\hline $\begin{array}{l}\mathrm{CO}+\mathrm{H}_{2} \mathrm{O} \rightarrow \mathrm{H}_{2}+\mathrm{CO}_{2} \\
\text { Syntrophic fatty acid oxidation }\end{array}$ & \multicolumn{2}{|c|}{ Syntrophic fatty acid oxidation } & Calculated \\
\hline $\mathrm{CH}_{3} \mathrm{CH}_{2} \mathrm{COOH}+2 \mathrm{H}_{2} \mathrm{O} \rightarrow \mathrm{CH}_{3} \mathrm{COOH}+3 \mathrm{H}_{2}+\mathrm{CO}_{2}$ & 0.33 & 1 & [31] \\
\hline $\mathrm{CH}_{3} \mathrm{COOH}+2 \mathrm{H}_{2} \mathrm{O} \rightarrow 4 \mathrm{H}_{2}+2 \mathrm{CO}_{2}$ & 0.33 & 1 & {$[31]$} \\
\hline \multicolumn{4}{|l|}{ Methanogenesis } \\
\hline $4 \mathrm{H}_{2}+\mathrm{CO}_{2} \rightarrow \mathrm{CH}_{4}+2 \mathrm{H}_{2} \mathrm{O}$ & 0.5 & 2 & [32] \\
\hline $\mathrm{CH}_{3} \mathrm{COOH} \rightarrow \mathrm{CO}_{2}+\mathrm{CH}_{4}$ & 0.5 & 2 & Calculated \\
\hline
\end{tabular}

\section{Results and Discussion}

\subsection{Enrichment of mesophilic and thermophilic mixed cultures}

A mixture of mesophilic anaerobic sludges was used as initial inoculum in a mesophilic and a thermophilic microbial enrichment to generate two stable enriched cultures with the ability to convert syngas into $\mathrm{CH}_{4}$ and $\mathrm{CO}_{2}$ as the only end 
synthesis gas, both mesophilic and thermophilic enrichment cultures presented hydrogenotrophic and carboxydotrophic activity. Both enrichment cultures were able to convert synthesis gas into $\mathrm{CH}_{4}$ as the main product from the first transfer of the enrichment, with only a short lag phase of around 2 days. The native carboxydotrophic ability of the anaerobic sludge was anticipated, since $\mathrm{CO}$ is a necessary intermediate for the autotrophic fixation of $\mathrm{CO}_{2}$ by acetogenic bacteria and for the aceticlastic energy metabolism of methanogenic archaea [33, 34]. However, more striking was the fact that the thermophilic enrichment culture did not present any apparent negative effect caused by the drastic change in incubation temperature at transfer T0 when compared to the mesophilic enrichment culture. Similar observations were made by Sipma et al. [14] when incubating a mesophilic anaerobic sludge at $55^{\circ} \mathrm{C}$ using $\mathrm{CO}$ as the only carbon and energy source, as they observed that the anaerobic sludge became rapidly adapted to the higher incubation temperature. This suggests that thermophilic microorganisms prevail in mesophilic anaerobic sludge microbial communities, and illustrates the high adaptability of mixed cultures when facing drastic changes in operating conditions.

The product recovery of the fermentations carried out by the mesophilic and the thermophilic cultures was relatively stable along the enrichment (fig. 1). The contribution of the residual activity of the inoculum to the total product recovery was only significant at transfer $\mathrm{T} 0$, where the production of acetate and $\mathrm{CH}_{4}$ in control experiments corresponded to $6.6 \%$ and $14.1 \%$ of the total product recovery for the mesophilic and the thermophilic enrichment cultures, respectively (fig. 1). Both enrichments rapidly reached a stable activity with an average $\mathrm{CH}_{4}$ yield in the last four transfers of $83.1 \pm 1.5 \%$ of the stoichiometric yield at mesophilic conditions and $90.1 \pm 1.6 \%$ at thermophilic conditions. However, the mesophilic enrichment presented acetate accumulation at transfer $\mathrm{T} 1$ as the culture was transferred before acetate could be fully converted to $\mathrm{CH}_{4}$. Consequently, the fermentation time was extended considerably in subsequent transfers to avoid washing out the aceticlastic methanogenic microbial group from the enrichment culture. In turn, the enrichment at thermophilic conditions allowed much faster transfers of the culture with no negative effects on the product selectivity towards $\mathrm{CH}_{4}$, since significant acetate production was only observed at the beginning of the enrichment (fig. 1).

The results obtained here for both the mesophilic and the thermophilic enrichments differed quite significantly from previous enrichment studies. A study on the enrichment of a thermophilic mixed culture reported that the $\mathrm{CH}_{4}$ production was suppressed along the microbial enrichment, and this was attributed to the inhibition of methanogenesis by the presence of $\mathrm{CO}$ [15]. However, in their study, the initial $\mathrm{P}_{\mathrm{CO}}$ was increased from 0.09 atm to $0.18 \mathrm{~atm}$ at the third transfer, which probably limited the adaptability of the culture due to the advanced stage of the enrichment, as it is likely that the enrichment had initially selected for methanogenic species with low tolerance to CO. In the present study, the initial $\mathrm{P}_{\mathrm{CO}}$ was kept constant at $0.4 \mathrm{~atm}$ along the whole thermophilic microbial enrichment, which probably favored the prompt selection of hydrogenotrophic methanogenic species with higher tolerance to $\mathrm{CO}$, allowing a complete conversion of syngas into $\mathrm{CH}_{4}$. Similarly, recent work on the enrichment of mesophilic mixed cultures using a multi-orifice baffled bioreactor (MOBB) sludge as initial inoculum reported a partial conversion of syngas into $\mathrm{CH}_{4}$ with acetate accumulation in the fermentation broth, which was attributed to a possible inhibition of aceticlastic methanogens due to the toxicity of CO [16]. In the present study, similar observations were made at transfer $\mathrm{T} 1$, where acetate started accumulating in the fermentation broth possibly due to inhibition of aceticlastic methanogens (fig. 1a). However, in this case, extending the fermentation time 
enabled the activity of the aceticlastic methanogenic microbial trophic group once $\mathrm{CO}$ was depleted, and thus, allowed the

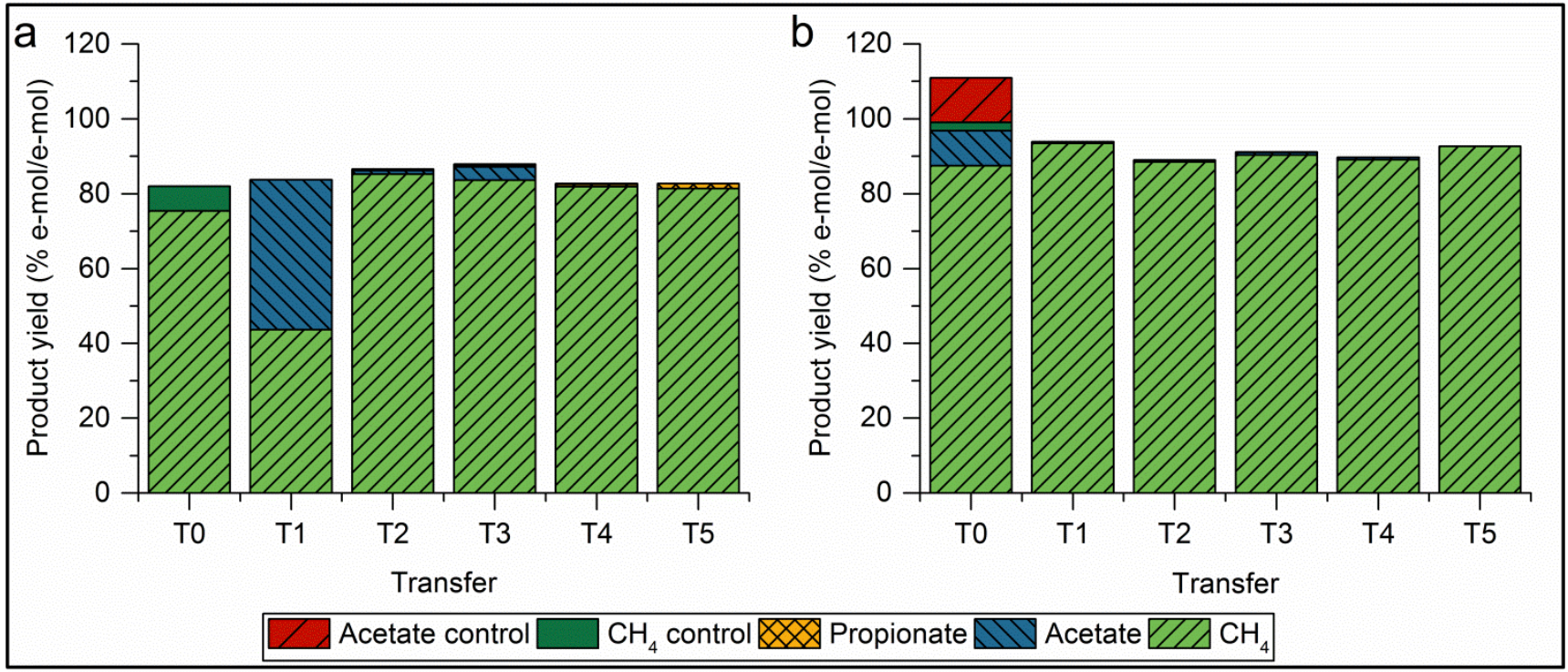

Figure 1. a. Product yields and total product recovery for the mesophilic culture along the enrichment. b. Product yields and total product recovery for the thermophilic culture along the enrichment. The product yields are given as percentage of the stoichiometric yield $(\%$ e$\mathrm{mol} / \mathrm{e}-\mathrm{mol}$ ) and correspond to the duplicate experiment used to inoculate the subsequent fermentation. Product yields from control experiments correspond to the estimated contribution of the organic matter present in the inoculum to the overall product recovery. Note that product yield observed in control experiments was negligible after transfer T0.

\subsection{Identification of catabolic routes and their specific activities}

The microbial enrichments, carried out in batch mode, were expected to select for the fastest growing microbial trophic groups at mesophilic and thermophilic conditions, diverting thus the carbon flux through the most efficient catabolic routes converting syngas into $\mathrm{CH}_{4}$ and $\mathrm{CO}_{2}$ in each case. Noticeable differences were found when comparing the fermentation profiles of the two enriched microbial consortia, which suggested different patterns of activity. The fermentation of syngas by the mesophilic enriched consortium typically resulted in transient production of acetate as intermediate product and propionate as a minor end by-product, while the evolution of intermediate products was not apparent when using the thermophilic enriched culture (fig. 2). Additionally, the maximum specific $\mathrm{CH}_{4}$ productivity of the mesophilic enriched consortium was one order of magnitude lower than that of the thermophilic consortium, namely $1.83 \pm 0.27$ and $33.48 \pm 0.90$ mmol CH$/ \mathrm{g} \mathrm{VSS} / \mathrm{h}$ respectively (table 4), which also indicated significant differences in the catabolic routes employed by each enriched microbial consortium since such difference in $\mathrm{CH}_{4}$ productivity could not be solely attributed to the anticipated increase in reaction rates due to the increase of incubation temperature. 


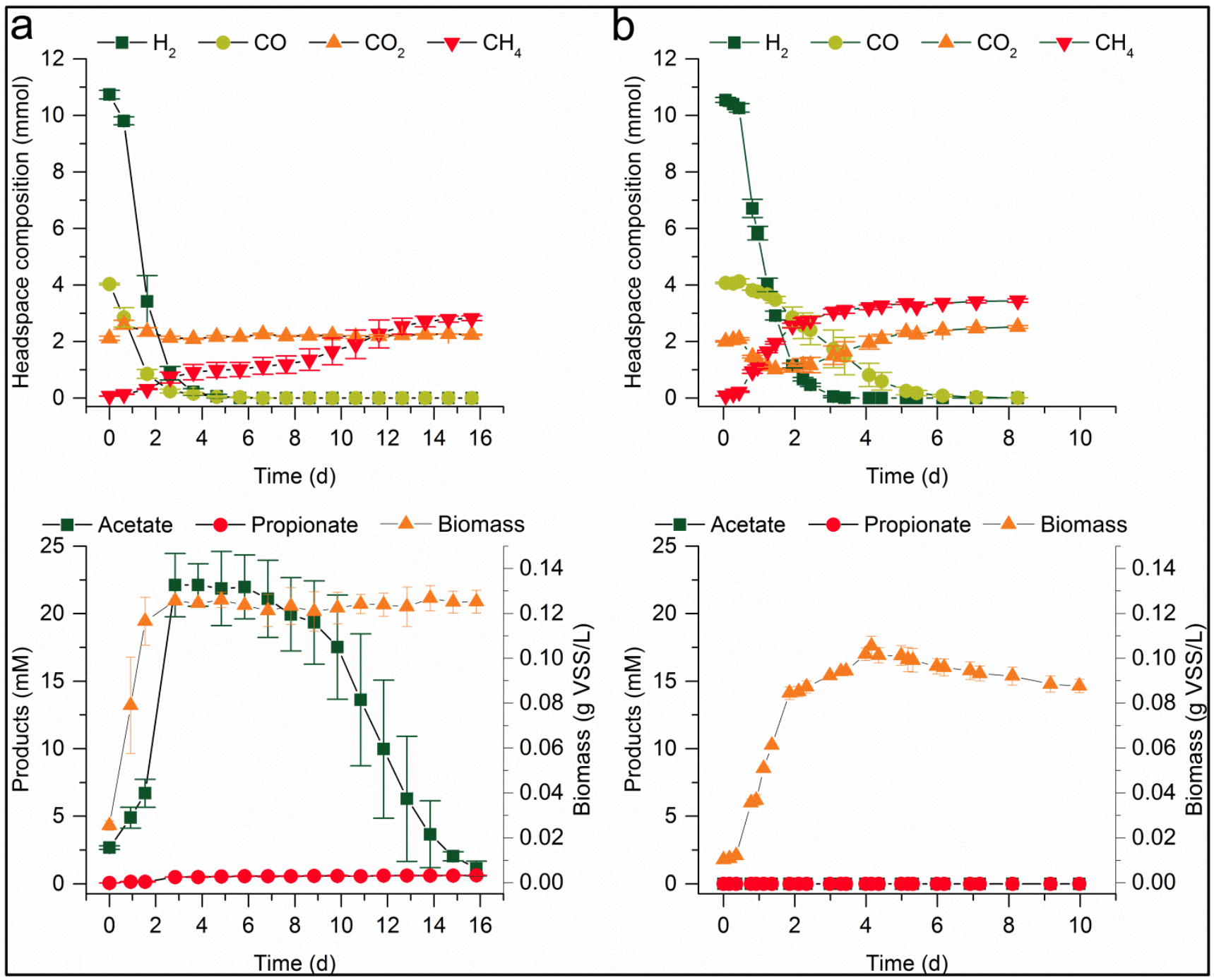

Figure 2. a. Fermentation profile for the mesophilic enriched microbial consortium after 6 transfers for substrates, products and biomass, respectively. b. Fermentation profile for the thermophilic enriched microbial consortium after 6 transfers for substrates, products and biomass, respectively.

5 The conversion of $\mathrm{CO}$ by the mesophilic and the thermophilic microbial consortium using BES for inhibiting methanogenic archaea resulted in the production of different metabolites, which indicated that the microbial trophic group metabolizing CO was different in each consortium (table 3 and Online Resource 1 - fig. S1a). The mesophilic enriched consortium was found to produce acetate as the main end-product $(0.17 \pm 0.01 \mathrm{~mol} / \mathrm{mol} \mathrm{CO})$ and propionate as a secondary metabolite $(0.01 \pm 0.00 \mathrm{~mol} / \mathrm{mol} \mathrm{CO})$ (table 3$)$. Several microbial groups have been reported to grow on CO producing significant amounts of acetic acid including carboxydotrophic acetogens, methanogens, hydrogenogens and sulfate-reducers [11, 3537]. Nonetheless, among these microbial groups, only carboxydotrophic acetogens have been described to produce acetic acid as the main product at mesophilic conditions. Additionally, the addition of the methanogenic inhibitor BES and the lack of sulfate in the growth medium prevented the growth of carboxydotrophic methanogens and sulfate-reducers, leading thus to the conclusion that carboxydotrophic acetogens were the microbial group responsible for the conversion of $\mathrm{CO}$ at 
1 mesophilic conditions. In turn, the conversion of CO by the thermophilic enriched consortium in presence of BES resulted

2 in the production of $\mathrm{H}_{2}$ as the main end-product $(0.68 \pm 0.01 \mathrm{~mol} / \mathrm{mol} \mathrm{CO})$ and acetic acid as the only secondary metabolite

3 (0.04 $\pm 0.01 \mathrm{~mol} / \mathrm{mol} \mathrm{CO})$ (table 3 and Online Resource 1 - fig. S1b). However, acetic acid was not observed as intermediate product when the thermophilic microbial consortium was exposed to syngas (fig. 2B), and no aceticlastic activity was found in this microbial consortium (table 3). This indicated that acetic acid was produced only when CO was used as the sole carbon source, which could only be explained by a partial metabolic shift from hydrogenogenesis to acetogenesis during the conversion of CO. Such a metabolic shift has been previously reported for the hydrogenogenic species Carboxydothermus hydrogenoformans, where the shift towards acetogenesis was attributed to the accumulation of $\mathrm{CO}_{2}$ in the gas phase [37]. Thus, the product profile found in the experiments at thermophilic conditions using $\mathrm{CO}$ is probably the result of strictly hydrogenogenic growth being partially inhibited by the accumulation of $\mathrm{H}_{2}$ and $\mathrm{CO}_{2}$ rather than simultaneous acetogenic and hydrogenogenic growth.

Table 3. Product yields and overall product recovery for the specific activity tests using the mesophilic and the thermophilic enriched microbial consortia.

\begin{tabular}{|c|c|c|c|c|c|}
\hline & $\begin{array}{l}\text { Product recovery } \\
(\% \text { e-mol/e-mol })\end{array}$ & $\begin{array}{c}\text { Acetate yield } \\
(\mathrm{mol} / \mathrm{mol})\end{array}$ & $\begin{array}{c}\text { Propionate yield } \\
(\mathrm{mol} / \mathrm{mol})\end{array}$ & $\begin{array}{c}\mathrm{H}_{2} \text { yield } \\
(\mathrm{mol} / \mathrm{mol})\end{array}$ & $\begin{array}{l}\mathrm{CH}_{4} \text { yield } \\
(\mathrm{mol} / \mathrm{mol}) \\
\end{array}$ \\
\hline \multicolumn{6}{|c|}{ Mesophilic microbial consortium } \\
\hline $\mathrm{CO}+\mathrm{BES}$ & $73.7 \pm 3.9$ & $0.17 \pm 0.01$ & $0.01 \pm 0.00$ & - & - \\
\hline $\mathrm{H}_{2} / \mathrm{CO}_{2}+\mathrm{BES}$ & $84.7 \pm 2.5$ & $0.21 \pm 0.01$ & - & - & - \\
\hline $\mathrm{H}_{2} / \mathrm{CO}_{2}{ }^{\mathrm{a}}$ & $92.8 \pm 0.3^{\mathrm{a}}$ & - & - & - & $0.23 \pm 0.00^{\mathrm{a}}$ \\
\hline Acetate & $81.5 \pm 0.9$ & - & - & - & $0.82 \pm 0.01$ \\
\hline $\mathrm{H}_{2} / \mathrm{CO}_{2}+\mathrm{CO}$ & $81.5 \pm 0.1$ & - & $0.004 \pm 0.000$ & - & $0.20 \pm 0.00$ \\
\hline \multicolumn{6}{|c|}{ Thermophilic microbial consortium } \\
\hline $\mathrm{CO}+\mathrm{BES}$ & $84.6 \pm 2.7$ & $0.04 \pm 0.01$ & - & $0.68 \pm 0.01$ & - \\
\hline $\mathrm{H}_{2} / \mathrm{CO}_{2}+\mathrm{BES}$ & & & No activity & & \\
\hline $\mathrm{H}_{2} / \mathrm{CO}_{2}$ & $91.4 \pm 0.9$ & - & - & - & $0.23 \pm 0.00$ \\
\hline Acetate & & & No activity & & \\
\hline $\mathrm{H}_{2} / \mathrm{CO}_{2}+\mathrm{CO}$ & $92.2 \pm 1.7$ & - & - & - & $0.23 \pm 0.00$ \\
\hline
\end{tabular}

aThe product recovery and the $\mathrm{CH}_{4}$ yield corresponds to the overall yield including the conversion of acetic acid through aceticlastic methanogenesis. The specific hydrogenotrophic $\mathrm{CH}_{4}$ yield and product recovery corresponds to $0.24 \pm 0.01 \mathrm{~mol} / \mathrm{mol} \mathrm{H}_{2}$ and $95.4 \pm 5.6 \%$, respectively.

Significant differences were also found when studying the catabolic routes for the conversion of $\mathrm{H}_{2} / \mathrm{CO}_{2}$ employed by each enriched microbial consortium. The experiments using the mesophilic enriched consortium with $\mathrm{H}_{2} / \mathrm{CO}_{2}$ as the sole substrate and addition of BES resulted in the production of acetic acid as the only end-metabolite $\left(0.21 \pm 0.01 \mathrm{~mol} / \mathrm{mol}_{2}\right)$, while in the experiments without BES addition, both acetic acid and methane were initially produced upon consumption of $\mathrm{H}_{2} / \mathrm{CO}_{2}$ and the acetic acid was further converted to $\mathrm{CH}_{4}$ in a later stage of the fermentation (overall $\mathrm{CH}_{4}$ yield of $0.23 \pm 0.00$ $\mathrm{mol} / \mathrm{mol} \mathrm{H} \mathrm{H}_{2}$ and estimated $\mathrm{CH}_{4}$ yield for the direct conversion of $\mathrm{H}_{2} / \mathrm{CO}_{2}$ of $\left.0.24 \pm 0.01 \mathrm{~mol} / \mathrm{mol} \mathrm{H}_{2}\right)($ Online Resource 1 , fig. $\mathrm{S} 2 \mathrm{a}, \mathrm{S} 3 \mathrm{a}$ and $\mathrm{S} 4 \mathrm{a}$ ). On the other hand, the thermophilic consortium did not present any microbial activity in experiments with BES and acetate addition, and $\mathrm{H}_{2} / \mathrm{CO}_{2}$ was found to be converted strictly to $\mathrm{CH}_{4}$ when BES was not added to the growth medium, resulting in a $\mathrm{CH}_{4}$ yield of $0.23 \pm 0.00 \mathrm{~mol} / \mathrm{mol} \mathrm{H}_{2}$ (Online Resource 1 , fig. S2b, S3b and S4b). This 
1 indicated that the thermophilic enriched consortium metabolized $\mathrm{H}_{2} / \mathrm{CO}_{2}$ strictly through hydrogenotrophic methanogenesis,

2 while in the mesophilic enriched consortium, both homoacetogenesis and hydrogenotrophic methanogenesis co-existed and

3 competed for this substrate. The latter was further supported by the high similarity between the specific activity rates of the

4 homoacetogenic and the hydrogenotrophic methanogenic microbial groups found for the mesophilic enriched consortium

\section{5 (table 4).}

6 Overall, the analysis of the patterns of activity of each microbial consortium revealed that the enrichment at different 7 incubation temperatures resulted in the development of two enriched consortia with totally different levels of complexity in 8 terms of microbial community structure, and activity rates (table 4). As a result of the enrichment, the mesophilic enriched 9 consortium presented a more intricate metabolic network composed by four different microbial trophic groups where 10 aceticlastic methanogenesis contributed to $64.9 \pm 8.3 \%$ of the $\mathrm{CH}_{4}$ production, with the rest being produced through 11 hydrogenotrophic methanogenesis. Thus, based on the maximum specific activities and productivities determined for this 12 microbial consortium, at mesophilic conditions, aceticlastic methanogenesis was the main rate-limiting step of the conversion of syngas into $\mathrm{CH}_{4}$ (table 4). In turn, the enrichment at thermophilic conditions led to a much simpler metabolic network based on $\mathrm{H}_{2}$ as the only intermediate product, resulting in the syntrophic association of only two different microbial trophic groups. This allowed achieving a more direct and much faster conversion of syngas into $\mathrm{CH}_{4}$ due to the higher turnover rates of $\mathrm{H}_{2}$ when compared to that of acetate (table 4). Additionally, the lower complexity of the thermophilic enriched consortium could also explain the higher overall $\mathrm{CH}_{4}$ yield observed in experiments for syngas conversion at thermophilic conditions, as the involvement of less intermediate steps, mostly in the conversion of $\mathrm{H}_{2}$, reduced the carbon and energy losses during the microbial conversion (table 3).

The specific activity tests allowed for determining the biomass yield for each microbial group composing the mesophilic and the thermophilic enriched consortia (table 4). The biomass yields were consistent with the product recoveries found for each experiment since there is a reversely proportional correlation between them, where higher product recovery resulted in a lower biomass yield for the corresponding microbial group with the exception of the experiment with $\mathrm{H}_{2} / \mathrm{CO}_{2}$ at mesophilic conditions (table 3 and 4). The carboxydotrophic acetogenic microbial group was found to have the highest biomass yield, which could be explained by the high ATP yield of their metabolic pathway compared to the rest (table 2). This probably favored the fact that growth of the aceticlastic methanogenic microbial group was not noticeable during the late stage of the fermentation of syngas at mesophilic conditions (fig. 2a).

Table 4. Biomass yield and specific activities and productivities for the different microbial groups present in the mesophilic and the thermophilic enriched microbial consortia.

\begin{tabular}{|c|c|c|c|c|c|c|c|c|}
\hline & \multirow{2}{*}{$\begin{array}{c}\text { Biomass } \\
\text { yield } \\
\text { (g VSS/mol } \\
\text { substrate) }\end{array}$} & \multicolumn{3}{|c|}{$\begin{array}{c}\text { Max. Specific activity } \\
\text { (mmol substrate/g VSS/h) }\end{array}$} & \multicolumn{4}{|c|}{$\begin{array}{l}\text { Max. Specific productivity } \\
\text { (mmol product/g VSS/h) }\end{array}$} \\
\hline & & $\mathrm{H}_{2}$ & $\mathrm{CO}$ & Acetate & Acetate & Propionate & $\mathrm{H}_{2}$ & $\mathrm{CH}_{4}$ \\
\hline \multicolumn{9}{|c|}{ Mesophilic enriched consortium } \\
\hline $\begin{array}{l}\text { Carboxydotrophic } \\
\text { acetogens }\end{array}$ & $2.45 \pm 0.06$ & - & $14.18 \pm 2.31$ & - & $2.53 \pm 0.64$ & $0.18 \pm 0.03$ & - & - \\
\hline
\end{tabular}




\begin{tabular}{|c|c|c|c|c|c|c|c|c|}
\hline Homoacetogens & $0.54 \pm 0.03$ & $49.14 \pm 10.70$ & - & - & $7.36 \pm 1.62$ & - & - & - \\
\hline $\begin{array}{l}\text { Hydrogenotrophic } \\
\text { methanogens }^{\mathrm{a}}\end{array}$ & $0.72 \pm 0.03^{\mathrm{a}}$ & $46.12 \pm 5.50^{\mathrm{a}}$ & - & - & - & - & - & $11.00 \pm 1.31^{\mathrm{a}}$ \\
\hline $\begin{array}{l}\text { Aceticlastic } \\
\text { methanogens }\end{array}$ & $0.57 \pm 0.06$ & - & - & $6.65 \pm 1.77$ & - & - & - & $6.44 \pm 0.54$ \\
\hline $\begin{array}{l}\text { All microbial } \\
\text { groups }\end{array}$ & $0.87 \pm 0.02$ & $27.45 \pm 1.23$ & $14.87 \pm 0.59$ & - & $5.26 \pm 0.91$ & $0.10 \pm 0.00$ & - & $1.83 \pm 0.27$ \\
\hline
\end{tabular}

Thermophilic enriched consortium

\begin{tabular}{l|c|ccc|ccc}
$\begin{array}{l}\text { Carboxydotrophic } \\
\text { hydrogenogens }\end{array}$ & $0.82 \pm 0.01$ & - & $52.35 \pm 1.72$ & - & $1.61 \pm 0.42$ & - & $44.95 \pm 4.11$ \\
$\begin{array}{l}\text { Hydrogenotrophic } \\
\text { methanogens }\end{array}$ & $0.51 \pm 0.01$ & $244.26 \pm 12.87$ & - & - & - & - & - \\
$\begin{array}{l}\text { All microbial } \\
\text { groups }\end{array}$ & $0.66 \pm 0.01$ & $165.75 \pm 4.53$ & $12.43 \pm 1.16$ & - & - & - & - \\
\hline
\end{tabular}

1 aThe biomass yield, the maximum specific activity and productivity for hydrogenotrophic methanogens was estimated based on the

2 biomass and acetate yield of homoacetogens determined in the experiments with $\mathrm{H}_{2} / \mathrm{CO}_{2}$ with $\mathrm{BES}$ addition.

3 Previous work on the identification of the catabolic routes for the conversion of $\mathrm{CO}$ to $\mathrm{CH}_{4}$ showed that the main $\mathrm{CO}$

4 conversion pathways shifted from acetogenesis to hydrogenogenesis when increasing the incubation temperature from $45^{\circ} \mathrm{C}$

5 onwards [14]. However, several studies focusing on the conversion of $\mathrm{CO}$ using different anaerobic sludges showed that,

6 despite the shift in the main catabolic routes between carboxydotrophic acetogenesis and hydrogenogenesis, both of these

7 reactions were available to the anaerobic sludge and occurred simultaneously during the conversion towards $\mathrm{CH}_{4}[13,14]$,

8 [38]. In this study, the mesophilic enriched consortium was found to convert CO strictly through carboxydotrophic

9 acetogenesis, while the thermophilic converted CO exclusively via carboxydotrophic hydrogenogenesis. Similarly, several

10 studies showed that there is a strong competition for $\mathrm{H}_{2}$ between homoacetogens and hydrogenotrophic methanogens in

11 both mesophilic and thermophilic anaerobic sludges, although hydrogenotrophic methanogenesis is clearly favored at

12 thermophilic conditions [39, 40]. In this study, a strong competition was also found between homoacetogens and

13 hydrogenotrophic methanogens at mesophilic conditions, whereas hydrogenotrophic methanogenesis was the only $\mathrm{H}_{2} / \mathrm{CO}_{2}$

14 microbial conversion activity found at thermophilic conditions. Therefore, it seems that the microbial enrichment procedure

15 applied in the present study based on batch operation and the incubation temperature selected the most efficient and fastest

16 growing microbial groups at the specific conditions used, enhancing the carbon flux through their corresponding catabolic

17 pathways and demoting the slower pathways to a negligible activity.

\subsection{Microbial composition of enriched cultures}

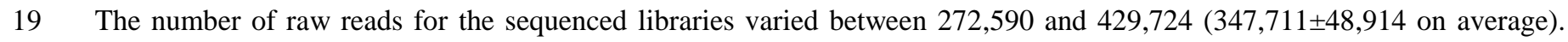

20 The number of OTUs generated using the V3-V4 region primer set corresponded to 2,373, while for the V4-V5 primer set

21 corresponded to 2,285 OTUs. The percentage of reads mapped to OTUs ranged from a minimum of $65.7 \%$ for the anaerobic

22 sludge used as initial inoculum to a maximum of $95.5 \%$ for the thermophilic enriched microbial consortium. The reads not 
1 mapped corresponded to reads of lower quality, chimeric or to true biological sequences that were not found among the 2 OTUs (and were filtered out or wrongly assigned as chimeras). Despite small differences, the percentage of reads mapping 3 to specific taxonomic lineages was highly consistent for the two primer sets used, indicating that both of them could be used 4 for analysis of bacterial and archaeal communities in analyzed samples (Online Resource 1 - fig. S5 and Online Resource 2).

6 The anaerobic sludge used as inoculum for the enrichments was found to be significantly different from the mesophilic and the thermophilic enriched consortia. While it is difficult to point to the dominant genera in the anaerobic sludge samples as the percentage of reads mapping to OTUs unassigned at genus level corresponded to 69.7\% (fig. 3), the major phyla included Firmicutes, Proteobacteria, Bacteroidetes (26.4\%, 21.6\%, 21.1\% reads mapped, respectively, using 341F785R primer set). None of the genera identified in the anaerobic sludge was found in samples from the mesophilic or the thermophilic enriched consortium, which shows that the enrichment had a strong effect on the microbial composition of the cultures, reducing the complexity of the microbial communities. Alpha diversity, both in terms of the number of observed OTUs and calculated PD whole tree index (reflecting the phylogenetic distance between OTUs), was considerably higher in anaerobic sludge samples. Moreover, higher temperature conditions clearly resulted in less diverse microbial community (Online Resource 2).

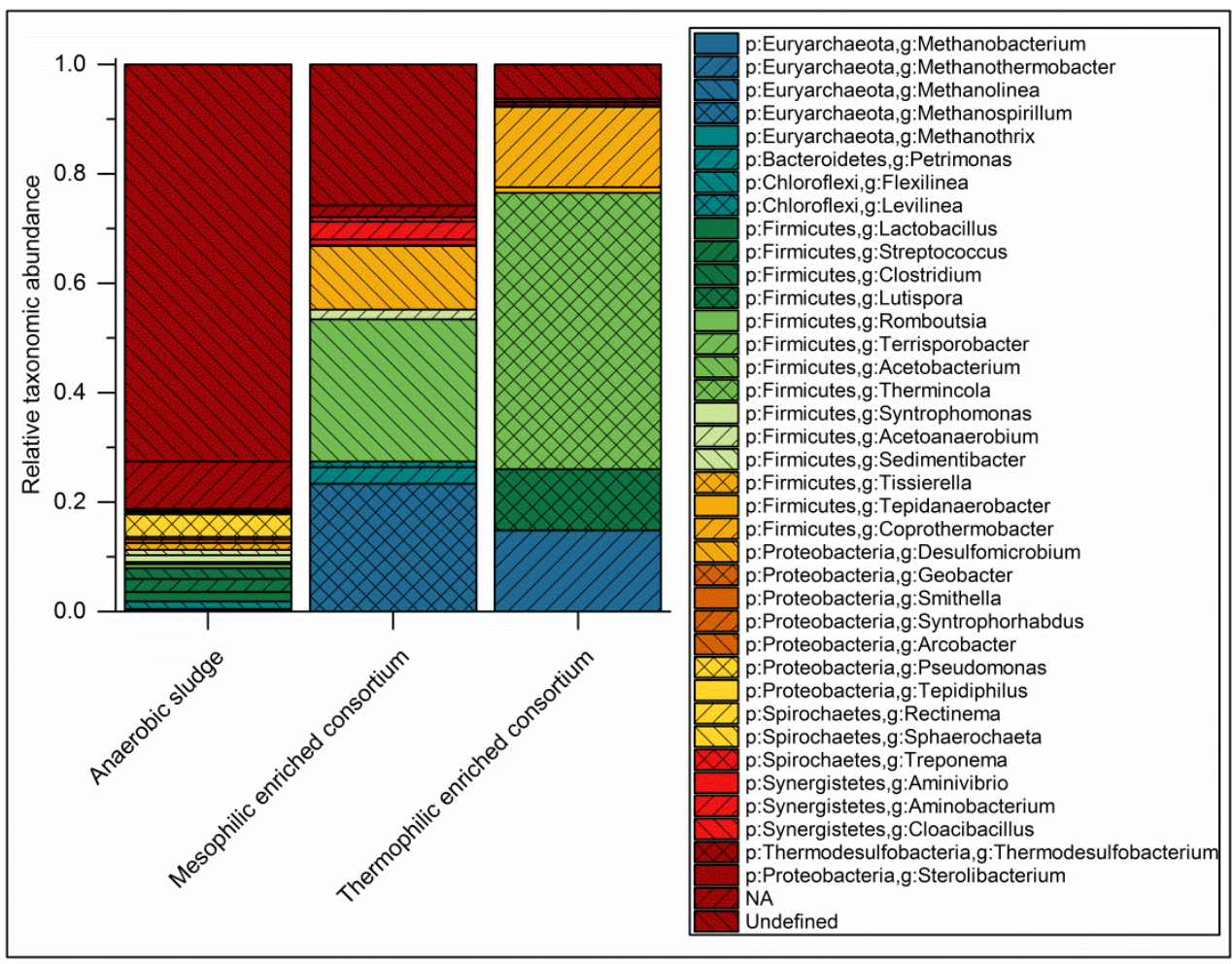

Figure 3. Average relative taxonomic abundance of triplicate samples for the initial inoculum used and the mesophilic and thermophilic enriched microbial consortia at genus level using the V3-V4 region primer set. NA corresponds to the sum of all genera with relative abundance below $0.5 \%$ in the individual samples before calculating the average. 
1 The mesophilic enriched consortium presented the highest microbial diversity at genus level among the two enriched

consortia. The dominant genera identified in this culture corresponded to Acetobacterium and Methanospirillum, with a percentage of reads mapping to these genera of $26.0 \%$ and $23.3 \%$, respectively (fig. 3 ). The species belonging to the genus Acetobacterium could not be identified; however, Acetobacterium species were likely responsible for the acetogenic growth on $\mathrm{CO}$ and $\mathrm{H}_{2} / \mathrm{CO}_{2}$ observed experimentally as several species from this genus have been found to be capable of carboxydotrophic and homoacetogenic growth [41]. While having in mind the lower confidence of species assignment in 16S amplicon sequencing studies [42], 15.8\% and 2.4\% of mapped 341F785R reads corresponded to OTUs assigned as Methanospirillum hungatei and Methanospirillum stamsii, respectively (fig. 3). It is likely that these or closely related species carried out the conversion of $\mathrm{H}_{2} / \mathrm{CO}_{2}$ into $\mathrm{CH}_{4}$ as both of them have been reported to be strict hydrogenotrophic methanogens [43]. Another genus identified with relatively high abundance was Desulfomicrobium (11.7\% of reads mapped), most likely corresponding to the species Desulfomicrobium escambiense. This relative abundance would suggest a possible role during the conversion of either $\mathrm{CO}$ or $\mathrm{H}_{2} / \mathrm{CO}_{2}$. However, several species closely related to Desulfomicrobium escambiense were found to be incapable of autotrophic growth in absence of sulfate and were not able to grow on acetate or propionate, for which the role of this species during the fermentation is yet to be elucidated since the only source of sulfur in the growth medium used was in the form of sulfide [44]. Aceticlastic methanogenesis is a metabolic process performed exclusively by methanogenic euryarchaea from the order Methanosarcinales [45]. While none of the observed OTUs in thermophilic enrichment samples were assigned to Methanosarcinales, less than $0.5 \%$ or reads corresponded to this order in mesophilic microbial community. The presence of aceticlastic methanogenic genera was in fact expected as this reaction was clearly observed in the specific activity tests. Low abundance of reads mapping to this microbial group could be explained by the fact that sampling was performed during the late exponential phase of the fermentation, possibly before the aceticlastic microbial group became active (fig. 2a). As shown in section 3.2, small amounts of propionate remained unconverted at the end of the fermentation, which would indicate that syntrophic fatty acid oxidizing bacteria did not play a significant role during the conversion. However, a small percentage of the reads mapped corresponded to the genus Geobacter ( $0.2 \%$ using V3-V4 primer set and 0.5\% using V4-V5 primer set), within which some species have been reported to be able of syntrophic fatty acid oxidation (Online resource 2, table 5) [46]. This indicates that propionate oxidation could have occurred to a limited extent during the fermentation. Two other genera belonging to the phylum Synergistetes corresponding to Aminivibrio and Aminobacterium were found to have higher relative abundances (1.0\% and 3.3\% of reads mapping to corresponding OTUs, respectively), although several species from these genera are not capable of syntrophic propionate or acetate oxidation and are probably associated with the degradation of amino acids originating from cell debris [47].

According to the results obtained in section 3.2, the thermophilic enriched consortium presented a simpler metabolic network when compared to that of the mesophilic enriched consortium. This is consistent with the results obtained in the analysis of the microbial composition. As shown in fig. 3, this microbial community was dominated by the genus Thermincola with a $47.9 \%$ of reads mapping to OTUs assigned to the species Thermincola carboxydiphila. Thermincola carboxydiphila has been reported to be an obligate carboxydotrophic hydrogenogen, which indicates that it was responsible 
1 for the conversion of $\mathrm{CO}$ into $\mathrm{H}_{2}$ and $\mathrm{CO}_{2}$ observed during the specific activity tests [48]. Similarly, the conversion of

$2 \quad \mathrm{H}_{2} / \mathrm{CO}_{2}$ into $\mathrm{CH}_{4}$ by hydrogenotrophic methanogens observed experimentally was confirmed by the fact that $14.8 \%$ of the 3 reads mapped to Methanothermobacter OTUs, as species belonging to this genus have been reported to be capable of autotrophic growth. In fact, the species Methanothermobacter thermoautotrophicus and Methanothermobacter marburgensis belonging to this genus were found to be capable of growth on both $\mathrm{H}_{2} / \mathrm{CO}_{2}$ and $\mathrm{CO}$ [9, 12]. Direct carboxydotrophic methanogenesis is not likely in this enriched culture though given the high relative abundance of the obligate carboxydotrophic hydrogenogen Thermincola carboxydiphila. Other species identified with a significant relative abundance were Lutispora thermophila and Coprothermobacter proteolyticus, representing a $9.6 \%$ and $14.7 \%$ of reads mapping to these species, respectively (fig. 3). Nonetheless, the role of these species during the fermentation is still uncertain as none of them is capable of autotrophic growth, and both are usually associated to environments with abundant proteinaceous material [49].

The analysis of the microbial composition of the enrichment cultures allowed for identifying the dominant microbial trophic groups present in both mesophilic and thermophilic microbial consortia. Overall, the microbial composition found was in agreement with the catabolic routes identified for each enriched consortium in section 3.2 as most of the dominant genera identified could be associated with a specific microbial activity. Additionally, the results obtained here were highly consistent with other batch enrichment studies performed at similar conditions as the genera Acetobacterium and Methanospirillum were also found to be predominant by Arantes et al. [16] at mesophilic conditions and the genus Thermincola by Alves et al. [15] at thermophilic conditions. This indicates that the microbial selection process is somewhat independent of the inoculum used for the enrichment and shows high reproducibility, since microbial communities with very different initial microbial composition converged towards enriched cultures with high similarity as a result of the microbial selection driven by the operating conditions used. However, more systematic enrichment and sequencing studies are necessary to investigate this phenomenon.

\subsection{Microbial selection and competition for common substrates}

In section 3.2 and 3.3, it was shown that the mesophilic and the thermophilic microbial enrichments resulted in the selection of different microbial groups, leading to different patterns of activity in each microbial consortium. As the enrichments were carried out in batch mode with initially high partial pressure of $\mathrm{H}_{2} / \mathrm{CO}_{2}$ and $\mathrm{CO}$, the microbial selection was expected to be dictated by the kinetic properties of the different microbial groups. However, several reactions composing the metabolic network of these enriched consortia proceed rather close to thermodynamic equilibrium, for which the competition for $\mathrm{H}_{2} / \mathrm{CO}_{2}$, $\mathrm{CO}$ or acetic acid could also be affected by possible bioenergetic limitations. Therefore, a thermodynamic analysis of the metabolic network was carried out in order to investigate further the effect of the temperature and other operational parameters on the rate of the biochemical reactions prevailing in each consortium and to identify possible bioenergetic limitations explaining their different patterns of activity.

The analysis of the effect of the temperature on the thermodynamics of $\mathrm{H}_{2}$-consuming reactions revealed that the $\Delta_{\mathrm{r}} \mathrm{G}_{\mathrm{T}}^{\prime}$ of 
1 temperature. As shown in fig. $4 \mathrm{a}$, the $\Delta_{\mathrm{r}} \mathrm{G}_{\mathrm{T}}^{\prime}$ of both homoacetogenesis and hydrogenotrophic methanogenesis become less 2 negative as the temperature increases, which indicates that the thermodynamic driving force for these reactions to proceed 3 forward decreases with increasing temperatures. Nonetheless, the fact that the thermodynamic potential factor $\left(\mathrm{F}_{\mathrm{T}}\right)$ 4 approaches 1 in both cases suggests that, in fact, the rate of these reactions would not be affected by changes in $\Delta_{\mathrm{r}} \mathrm{G}_{\mathrm{T}}^{\prime}$ as 5 these reactions would release enough free energy to satisfy the energy conservation requirements of their corresponding metabolic pathways regardless of the incubation temperature (fig. 4b). At the initial fermentation conditions, the activity rate of these reactions would then be strictly subject to kinetic control, which implies that the result of the competition for

$8 \mathrm{H}_{2}$ would be dependent on the maximum specific growth rate $\left(\mu_{\max }\right)$ of these two microbial groups. Therefore, the 9 competition for $\mathrm{H}_{2}$ would be expected to favor hydrogenotrophic methanogens when increasing the temperature as it has 10 been shown that the positive effect of the temperature on $\mu_{\max }$ is more pronounced for hydrogenotrophic methanogens, with 11 homoacetogens being able to compete for $\mathrm{H}_{2}$ only at psychrophilic and mesophilic conditions $[39,40,50]$. 


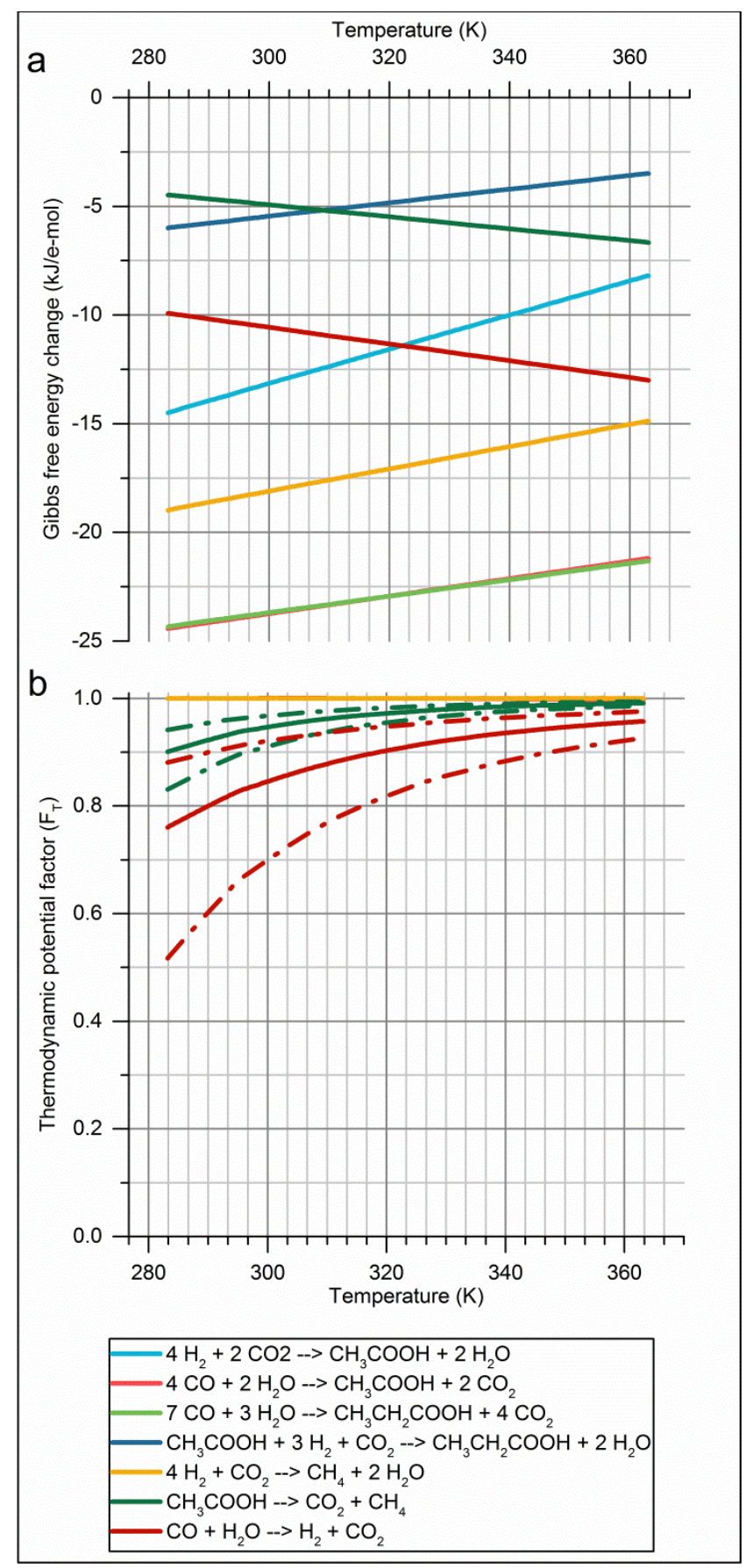

2 Figure 4. a. Gibbs free energy change as a function of temperature normalized to e-mol of electron donor for each of the biochemical reactions considered at the initial enrichment conditions. The operating conditions considered were $\mathrm{P}_{\mathrm{H} 2} \mathrm{of} 1.3 \mathrm{~atm}, \mathrm{P}_{\mathrm{CO} 2} \mathrm{of} 0.2 \mathrm{~atm}, \mathrm{P}_{\mathrm{CO}}$ of $0.4 \mathrm{~atm}$, acetic acid concentration of $0.001 \mathrm{M}$, propionate concentration of $0.0001 \mathrm{M}, \mathrm{pH} 7$ and ionic strength of $0.08 \mathrm{M}$. b. Thermodynamic potential factor $\left(\mathrm{F}_{\mathrm{T}}\right)$ as a function of temperature for each of the biochemical reactions considered at the initial enrichment conditions. Solid lines represent $\mathrm{F}_{\mathrm{T}}$ calculated using a $\Delta \mathrm{Gp}$ of $50 \mathrm{~kJ} / \mathrm{mol}$ of ATP. Dashed lines represent the upper and lower boundaries of $\mathrm{F}_{\mathrm{T}}$ when using a $\Delta \mathrm{Gp}$ of 45 and $55 \mathrm{~kJ} / \mathrm{mol}$ of ATP, respectively. 
1 The main $\mathrm{CO}$ conversion pathways identified in this study corresponded to carboxydotrophic acetogenesis and 2 hydrogenogenesis, found to be predominant at mesophilic and thermophilic conditions, respectively. Analyzing the $\Delta_{\mathrm{r}} \mathrm{G}_{\mathrm{T}}^{\prime}$ as 3 a function of temperature showed that both of these reactions should be feasible at the temperature range considered, with acetogenesis becoming less exergonic with increasing temperatures and hydrogenogenesis being favored by the increase of temperature (fig. 4a). However, the analysis of the $\mathrm{F}_{\mathrm{T}}$ revealed that, although the hydrogenogenesis is feasible at all temperatures, the rate of this reaction becomes thermodynamically limited at low temperatures due to the high initial $\mathrm{P}_{\mathrm{H} 2}$ used in the experiments. As illustrated in fig. $4 \mathrm{~b}$, this reaction approaches its limits of feasibility as the temperature decreases, with the $\mathrm{F}_{\mathrm{T}}$ decreasing from a minimum of 0.86 at $60{ }^{\circ} \mathrm{C}$ to 0.77 at $37{ }^{\circ} \mathrm{C}$ when considering a $\Delta \mathrm{G}_{\mathrm{p}}$ of $55 \mathrm{~kJ} / \mathrm{mol}$ of ATP and an ATP yield of $0.33 \mathrm{~mol} \mathrm{ATP} / \mathrm{mol} \mathrm{CO}$. This thermodynamic limitation is applicable only at the initial fermentation conditions with high $\mathrm{P}_{\mathrm{H} 2}$ though, as $\mathrm{F}_{\mathrm{T}}$ would rapidly approach 1 as soon as $\mathrm{H}_{2}$ started to be consumed. Nevertheless, this suggests that thermodynamics could have played a role in the microbial selection process during the enrichment at mesophilic conditions, as this initial thermodynamic limitation could have given an initial competitive advantage to the acetogenic microbial group. The kinetic properties of these microbial trophic groups appear to be consistent with the latter since carboxydotrophic acetogens have been shown to perform better at mesophilic conditions (with minimum reported doubling times of $1.5 \mathrm{~h}$ at mesophilic conditions [35] and $7 \mathrm{~h}$ at thermophilic conditions [51]), while the carboxydotrophic hydrogenogenic growth rate seems to be favored at thermophilic conditions (with minimum reported doubling times of $5.7 \mathrm{~h}$ at mesophilic conditions [52] and $1 \mathrm{~h}$ at thermophilic conditions [53]). Thus, both kinetics and thermodynamics may have contributed to the outcome of the competition for $\mathrm{CO}$ found at the experimental conditions tested.

The fermentation of synthesis gas at mesophilic conditions resulted in the accumulation of propionic acid as a minor end product, which was not completely converted to $\mathrm{CH}_{4}$. Navarro et al. [13] made similar observations when using anaerobic sludge for the biomethanation of $\mathrm{CO}$, as varying amounts of propionic acid were produced depending on the initial $\mathrm{P}_{\mathrm{CO}}$ used in batch experiments. The production of propionic acid could take place through several reactions e.g. through the direct conversion of $\mathrm{CO}$, or through the reduction of acetic acid using $\mathrm{H}_{2}$ and $\mathrm{CO}_{2}$. As shown in the thermodynamic analysis, both reactions are feasible at mesophilic conditions due to the high initial partial pressure of $\mathrm{CO}, \mathrm{H}_{2}$ and $\mathrm{CO}_{2}$ since $\Delta_{\mathrm{r}} \mathrm{G}_{\mathrm{T}}^{\prime}$ is negative and the $\mathrm{F}_{\mathrm{T}}$ value approaches 1 in both cases (fig. 4). Nevertheless, the fact that propionic acid was not produced in experiments using $\mathrm{H}_{2} / \mathrm{CO}_{2}$ and was produced only in experiments containing $\mathrm{CO}$ indicates that the direct conversion of $\mathrm{CO}$ into propionic acid was the most likely pathway. Therefore, propionic acid was probably a by-product of the carbon flux diverted towards biomass synthesis during the conversion of $\mathrm{CO}$ as this would be consistent with the high biomass yield observed for carboxydotrophic acetogens (table 4).

According to the catabolic routes identified in section 3.2, it seems that the main syntrophic interactions prevailing in the enriched microbial consortia were limited to cross-feeding relationships, since the participation of strict syntrophic microorganisms such as syntrophic fatty acid oxidizing bacteria could not be observed experimentally. Of course, it is likely that the microbial community as a whole benefited from the synergistic action of the different microbial groups involved in the conversion, e.g. the continuous removal of acetate and $\mathrm{H}_{2}$ by methanogenic archaea probably had a positive effect on the 
conversion of $\mathrm{CO}$ by carboxydotrophic acetogens and hydrogenogens, respectively. However, as shown in the specific activity tests, these reactions could easily proceed forward even when methanogenic growth was inhibited, indicating that their microbial interaction was not as necessary as it is the case for syntrophic fatty acid oxidizing bacteria. As discussed above, the experiments at mesophilic conditions resulted in the accumulation of propionate as a final product, which was apparently not converted through syntrophic propionate oxidation. Similarly, acetate was found to be converted strictly through aceticlastic methanogenesis with no apparent participation of syntrophic acetate oxidizers. Nevertheless, the presence of Geobacter sp. (with a relative read abundance of $0.5 \%$ using the V4-V5 primer set) suggested a limited participation of syntrophic fatty acid oxidation reactions along the fermentation. Additionally, other studies focusing on the biomethanation of $\mathrm{CO}$ and $\mathrm{H}_{2}$ have shown that both propionate and acetate can be converted through the microbial interaction between syntrophic fatty acid oxidizers and hydrogenotrophic methanogens [13,54]. This can be explained by the thermodynamic feasibility of these reactions under the specific operating conditions found in this study. The limits of thermodynamic feasibility as a function of a specific product or substrate for each reaction can be approximated based on the concentration at which $\mathrm{F}_{\mathrm{T}}$ reaches a value of 0 , as this indicates that the metabolism ceases and the biochemical reaction reaches its maximum threshold concentration of product or its minimum threshold concentration of substrate at which it is feasible. As shown in fig. 5b, the minimum threshold concentration of acetate for aceticlastic methanogens at the experimental conditions was estimated to range between $75 \mathrm{nM}$ and $600 \mathrm{nM}$, which is consistent with experimentally determined threshold acetate concentrations for this microbial group [55]. Considering the concentration of metabolites in the fermentation broth and the gas phase at the end of the experiments with syngas, the conversion of propionate to acetate, $\mathrm{H}_{2}$ and $\mathrm{CO}_{2}$ would then be thermodynamically feasible only at acetate concentrations either equal or below the minimum threshold for aceticlastic methanogens (fig. 5b). This indicates that aceticlastic methanogens were not able to keep the acetate concentration at levels low enough for allowing complete syntrophic propionate oxidation. Similarly, at the time of the fermentation with the maximum acetate concentration, the extent of the syntrophic interaction between hydrogenotrophic methanogens and syntrophic acetate oxidizers was intrinsically limited by the thermodynamic feasibility of these reactions, as hydrogenotrophic methanogenesis and syntrophic acetate oxidation reaction share the same minimum and maximum threshold $\mathrm{P}_{\mathrm{H} 2}$, respectively (fig. 5a). However, both syntrophic acetate and propionate oxidation reactions are at the edge of their feasibility with respect to the minimum threshold for hydrogenotrophic and aceticlastic methanogens, which suggests that these reactions could have taken place to a limited extent, keeping the concentration of acetate and propionate at their minimum threshold during the fermentation. Therefore, the fact that syntrophic fatty acid oxidation reactions had a limited participation during the fermentation and that aceticlastic methanogenesis was the dominant catabolic route converting acetate to $\mathrm{CH}_{4}$ cannot be attributed to kinetic competition, but to the limits of thermodynamic feasibility of these reactions under these specific operating conditions.

At mesophilic conditions, aceticlastic methanogenesis became the dominant catabolic route despite being the main ratelimiting step of the conversion due to the thermodynamic limitation of syntrophic acetate oxidation. However, syntrophic fatty acid oxidizers have been shown to be capable of fast growth with doubling times of 6-8 $\mathrm{h}$ at mesophilic conditions [46], which indicates that these should be able to outcompete aceticlastic methanogens as long as the syntrophic fatty acid 
1 oxidation is feasible. Therefore, the overall productivity of the mesophilic enriched consortium could be significantly 2 boosted by favoring operating conditions allowing the syntrophic acetate oxidation. One way of achieving this would be 3 reducing the $\mathrm{P}_{\mathrm{CO} 2}$ in the gas phase either by optimizing the initial composition of syngas or by supplying additional $\mathrm{H}_{2}$ in 4 order to increase the minimum threshold of acetate concentration for syntrophic acetate oxidizers, which would make 5 hydrogenotrophic methanogenesis the dominant $\mathrm{CH}_{4}$ production pathway. In this case, applying thermodynamic control for 6 driving a shift in the catabolic routes of the mesophilic enriched consortium towards syntrophic acetate oxidation would be 7 especially beneficial under continuous operating mode, as shorter hydraulic retention times (HRT) could be applied, 8 resulting in higher overall $\mathrm{CH}_{4}$ productivities. It should be noted though, that under continuous operation the gas conversion 9 efficiency would become a crucial parameter for keeping $\mathrm{P}_{\mathrm{H} 2}$ and $\mathrm{P}_{\mathrm{CO} 2}$ at levels low enough to allow a significant syntrophic 10 acetate oxidation. 


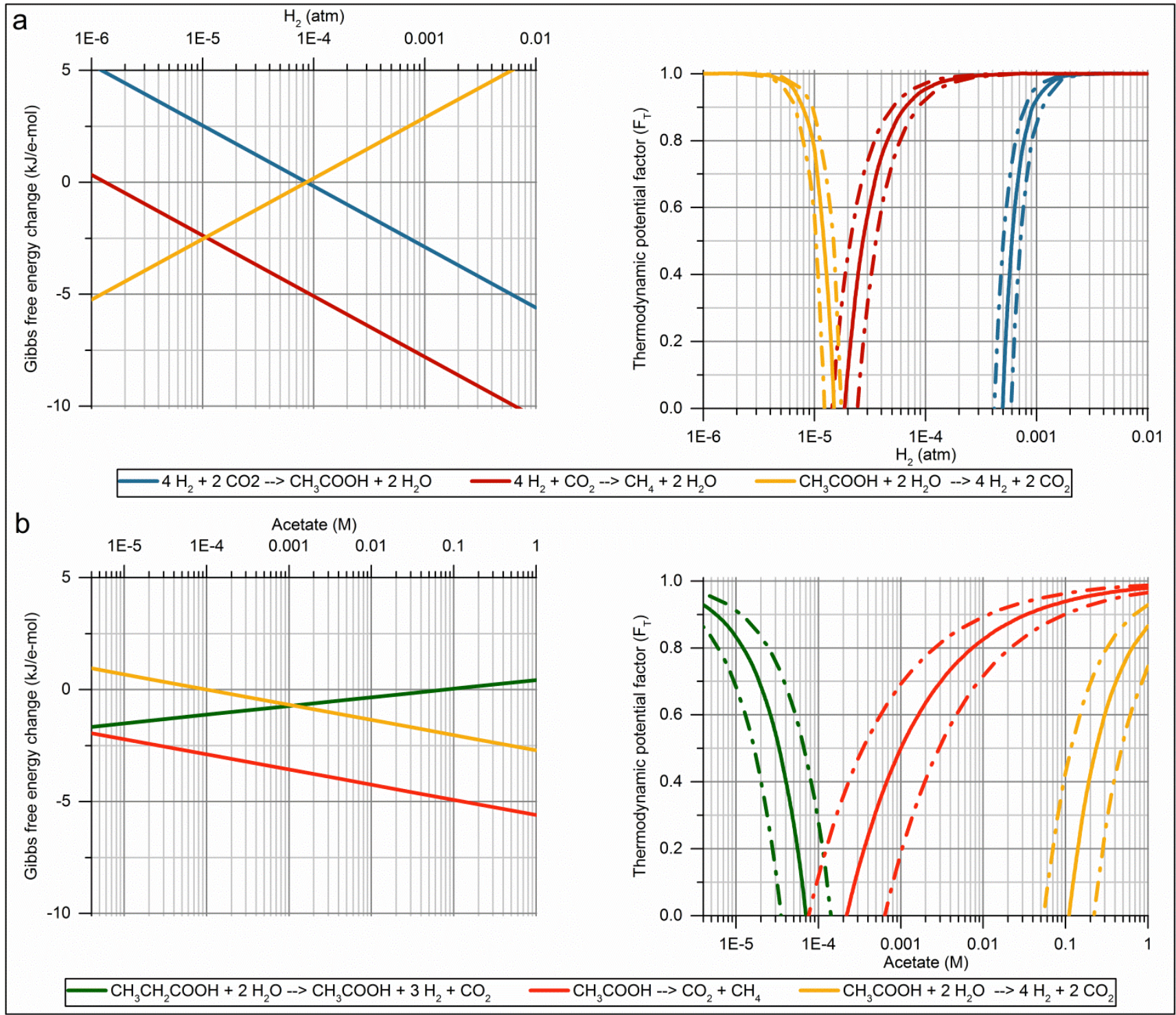

Figure 5. a. Gibbs free energy change $\left(\Delta_{\mathrm{r}} \mathrm{G}_{\mathrm{T}}^{\prime}\right)$ and thermodynamic potential factor $\left(\mathrm{F}_{\mathrm{T}}\right)$ as a function of $\mathrm{P}_{\mathrm{H} 2}$ for hydrogenotrophic methanogenesis, homoacetogenesis and syntrophic acetate oxidation at the fermentation time with maximum acetate concentration. The operating conditions considered were $\mathrm{P}_{\mathrm{CO} 2}$ of $0.2 \mathrm{~atm}, \mathrm{P}_{\mathrm{CH} 4}$ of $0.1 \mathrm{~atm}$, acetate concentration of $0.022 \mathrm{M}$, temperature of $37{ }^{\circ} \mathrm{C}$, $\mathrm{pH} 6.8$ and ionic strength of $0.08 \mathrm{M}$. b. Gibbs free energy change $\left(\Delta_{\mathrm{r}} \mathrm{G}^{\prime} \mathrm{T}\right)$ and thermodynamic potential factor $\left(\mathrm{F}_{\mathrm{T}}\right)$ as a function of acetate concentration for aceticlastic methanogenesis and syntrophic propionate and acetate oxidation at the final fermentation conditions. The operating conditions considered were $\mathrm{P}_{\mathrm{H} 2}$ of 0.00002 atm (determined by the minimum threshold of $\mathrm{H}_{2}$ for hydrogenotrophic methanogens (fig. 5a), $\mathrm{P}_{\mathrm{CO} 2}$ of $0.2 \mathrm{~atm}, \mathrm{P}_{\mathrm{CH} 4}$ of $0.28 \mathrm{~atm}$, propionate concentration of $0.0006 \mathrm{M}$, temperature of $37{ }^{\circ} \mathrm{C}$, pH 7 and ionic strength of $0.08 \mathrm{M}$. The $\Delta_{\mathrm{r}} \mathrm{G}_{\mathrm{T}}^{\prime}$ shown was normalized to e-mol of electron donor for each of the biochemical reactions considered. Solid lines for $\mathrm{F}_{\mathrm{T}}$ represent $\mathrm{F}_{\mathrm{T}}$ calculated using a $\Delta \mathrm{Gp}$ of $50 \mathrm{~kJ} / \mathrm{mol}$ of ATP. Dashed lines represent the upper and lower boundaries of $\mathrm{F}_{\mathrm{T}}$ when using a $\Delta \mathrm{Gp}$ of 45 and $55 \mathrm{~kJ} / \mathrm{mol}$ of ATP, respectively.

\section{Conclusions}

Highly specialized microbial consortia for the biomethanation of syngas at mesophilic and thermophilic conditions were obtained through enrichments in batch mode. Both microbial consortia were shown to be able to convert syngas into $\mathrm{CH}_{4}$ 
with high product selectivity, presenting a stable activity over several transfers. The $\mathrm{CH}_{4}$ yield obtained corresponded to $81.5 \pm 0.1 \%$ and $92.2 \pm 1.7 \%$ of the stoichiometric yield and the maximum specific $\mathrm{CH}_{4}$ productivity was $1.83 \pm 0.27$ and $33.48 \pm 0.90 \mathrm{mmol} \mathrm{CH} / \mathrm{g}$ VSS/h for the mesophilic and the thermophilic enriched consortium, respectively. The incubation temperature was found to be a crucial operating parameter affecting the microbial composition of the enriched cultures, the catabolic routes employed by each of them and the microbial activity rates. Both the specific activity tests and the microbial composition analysis confirmed that the mesophilic and the thermophilic enriched consortia presented drastically different patterns of activity. Additionally, the thermodynamic feasibility analysis of their metabolic networks revealed that the competition for common substrates was not solely driven by kinetic competition, as the thermodynamic limitation of several reactions under the experimental process conditions also played an important role defining the microbial structure of the enriched consortia and the dominant catabolic routes. As a result, the mesophilic enriched consortium presented a more intricate metabolic network than the thermophilic consortium, which ultimately limited the $\mathrm{CH}_{4}$ production rate due to the fact that aceticlastic methanogenesis was the dominant catabolic route leading to $\mathrm{CH}_{4}$. This indicates that, in principle, the thermophilic consortium could be more suitable for industrial applications owing to the higher $\mathrm{CH}_{4}$ production rate derived from the faster turnover rates of $\mathrm{H}_{2}$ as intermediate metabolite. However, the possibility of applying thermodynamic control over catabolic routes employed by the mesophilic enriched consortium, shifting from aceticlastic methanogenesis to syntrophic acetate oxidation, could also favor a significant improvement in the $\mathrm{CH}_{4}$ production rate both in batch and continuous processes as hydrogenotrophic methanogenesis would become the dominant methanogenic pathway.

\section{Acknowledgements}

This work was financially supported by the Technical University of Denmark (DTU) and Innovation Foundation-DK in the frame of SYNFERON project.

\section{Conflict of Interest}

The authors declare that they have no conflict of interest.

\section{References}

1. Grimalt-Alemany, A., Skiadas, I.V., and Gavala, H.N.: Syngas biomethanation: State-of-the-art review and perspectives. Biofuels, Bioprod Biorefining, 12, 139-158 (2018).

2. Cantera, S., Muñoz, R., Lebrero, R., Lopez, J.C., Rodríguez, Y., and García-Encina, P.A.: Technologies for the bioconversion of methane into more valuable products. Curr Opin Biotechnol, 50, 128-135 (2018).

3. Holm-Nielsen, J.B., Al Seadi, T., and Oleskowicz-Popiel, P.: The future of anaerobic digestion and biogas utilization. Bioresour Technol, 100, 5478-5484 (2009).

4. Batstone, D.J. and Virdis, B.: The role of anaerobic digestion in the emerging energy economy. Curr Opin Biotechnol, 27, 142-149 (2014). 
1 5. Hendriks, A.T.W.M. and Zeeman, G.: Pretreatments to enhance the digestibility of lignocellulosic biomass. Bioresour Technol, 100, 10-18 (2009).

6. Kumar, A., Jones, D.D., and Hanna, M.A.: Thermochemical Biomass Gasification: A Review of the Current Status of the Technology. Energies, 2, 556-581 (2009).

7. Asimakopoulos, K., Gavala, H.N., and Skiadas, I.V: Reactor systems for syngas fermentation processes : A review. Chem Eng J, 348, 732-744 (2018).

8. Luo, G. and Angelidaki, I.: Integrated Biogas Upgrading and Hydrogen Utilization in an Anaerobic Reactor Containing Enriched Hydrogenotrophic Methanogenic Culture. Biotechnol Bioeng, 109, 2729-2736 (2012).

9. Daniels, L., Fuchs, G., Thauer, R.K., and Zeikus, J.G.: Carbon Monoxide Oxidation by Methanogenic Bacteria. J Bacteriol, 132, 118-126 (1977).

10. O’Brien, J.M., Wolkin, R.H., Moench, T.T., Morgan, J.B., and Zeikus, J.G.: Association of hydrogen metabolism with unitrophic or mixotrophic growth of Methanosarcina barkeri on carbon monoxide. J Bacteriol, 158, 373-375 (1984).

11. Rother, M. and Metcalf, W.W.: Anaerobic growth of Methanosarcina acetivorans C2A on carbon monoxide: an unusual way of life for a methanogenic archaeon. Proc Natl Acad Sci U S A, 101, 16929-16934 (2004).

12. Diender, M., Pereira, R., Wessels, H.J.C.T., Stams, A.J.M., and Sousa, D.Z.: Proteomic Analysis of the Hydrogen and Carbon Monoxide Metabolism of Methanothermobacter marburgensis. Front Microbiol, 7, 1-10 (2016).

13. Navarro, S.S., Cimpoia, R., Bruant, G., and Guiot, S.R.: Biomethanation of Syngas Using Anaerobic Sludge: Shift in the Catabolic Routes with the CO Partial Pressure Increase. Front Microbiol, 7, 1-13 (2016).

14. Sipma, J., Lens, P.N.L., Stams, A.J.M., and Lettinga, G.: Carbon monoxide conversion by anaerobic bioreactor sludges. FEMS Microbiol Ecol, 44, 271-277 (2003).

15. Alves, J.I., Stams, A.J.M., Plugge, C.M., Alves, M.M., and Sousa, D.Z.: Enrichment of anaerobic syngas-converting bacteria from thermophilic bioreactor sludge. FEMS Microbiol Ecol, 86, 590-597 (2013).

16. Arantes, A.L., Alves, J.I., Stams, A.J.M., Alves, M.M., and Sousa, D.Z.: Enrichment of syngas-converting communities from a multi-orifice baffled bioreactor. Microbial Biotechnology (2017). doi:10.1111/17517915.12864 .

17. APHA: Standard Methods for the Examination of Water and Wastewater. American Public Health Association/American Water Works Association/Water Pollution Control Federation, Washington DC (1997). 
18. Takahashi, S., Tomita, J., Nishioka, K., Hisada, T., and Nishijima, M.: Development of a Prokaryotic Universal Primer for Simultaneous Analysis of Bacteria and Archaea Using Next-Generation Sequencing. PLoS One, 9, e105592 (2014).

19. Walters, W. et al:: Transcribed Spacer Marker Gene Primers for Microbial Community Surveys. mSystems, 1, e0009-15 (2015).

20. Martin, M.: Cutadapt removes adapter sequences from high-thoughput sequencing reads. EMBnet J, 17, 10-12 (2011).

21. Edgar, R.C.: UNOISE2: improved error-correction for Illumina 16S and ITS amplicon sequencing (2016).

22. Edgar, R.C.: SINTAX: a simple non-Bayesian taxonomy classifier for 16S and ITS sequences (2016).

23. Yarza, P. et al.: The All-Species Living Tree project: A 16S rRNA-based phylogenetic tree of all sequenced type strains. Syst Appl Microbiol, 31, 241-250 (2008).

24. Dhariwal, A., Chong, J., Habib, S., King, I.L., Agellon, L.B., and Xia, J.: MicrobiomeAnalyst: a web-based tool for comprehensive statistical, visual and meta-analysis of microbiome data. Nucleic Acids Res, 45, 180-188 (2018).

25. Alberty, R.A.: Thermodynamics of Biochemical Reactions. John Wiley \& Sons, Inc, New Jersey (2003).

26. Amend, J.P. and Shock, E.L.: Energetics of overall metabolic reactions of thermophilic and hyperthermophilic Archaea and bacteria. FEMS Microbiol Rev, 25, 175-243 (2001).

27. Steinbusch, K.J.J., Hamelers, H.V.M., and Buisman, C.J.N.: Alcohol production through volatile fatty acids reduction with hydrogen as electron donor by mixed cultures. Water Res, 42, 4059-4066 (2008).

28. Jin, Q. and Bethke, C.M.: The thermodynamics and kinetics of microbial metabolism. Am J Sci, 307, 643-677 (2007).

29. Grimalt-Alemany, A., Łężyk, M., Lange, L., Skiadas, I.V., and Gavala, H.N.: Enrichment of syngas-converting mixed microbial consortia for ethanol production and thermodynamics-based design of enrichment strategies. Biotechnol Biofuels, 11, 1-22 (2018).

30. Bertsch, J. and Müller, V.: Bioenergetic constraints for conversion of syngas to biofuels in acetogenic bacteria. Biotechnol Biofuels, 8, 1-12 (2015).

31. Lingen, H.J. Van, Plugge, C.M., Fadel, J.G., and Kebreab, E.: Thermodynamic Driving Force of Hydrogen on Rumen Microbial Metabolism : A Theoretical Investigation. 1-18 (2016). 
32. Kaster, A., Moll, J., Parey, K., and Thauer, R.K.: Coupling of ferredoxin and heterodisulfide reduction via electron bifurcation in hydrogenotrophic methanogenic archaea. 108, 2981-2986 (2011).

33. Diekert, G. and Wohlfarth, G.: Metabolism of homoacetogens. Antonie Van Leeuwenhoek, 66, 209-221 (1994).

34. Oelgeschläger, E. and Rother, M.: Carbon monoxide-dependent energy metabolism in anaerobic bacteria and archaea. Arch Microbiol, 190, 257-69 (2008).

35. Lorowitz, W.H. and Bryant, M.P.: Peptostreptococcus productus strain that grows rapidly with CO as the energy source. Appl Environ Microbiol, 47, 961-964 (1984).

36. Parshina, S.N., Kijlstra, S., Henstra, A.M., Sipma, J., Plugge, C.M., and Stams, A.J.M.: Carbon monoxide conversion by thermophilic sulfate-reducing bacteria in pure culture and in co-culture with Carboxydothermus hydrogenoformans. Appl Microbiol Biotechnol, 68, 390-396 (2005).

37. Henstra, A.M. and Stams, A.J.M.: Deep Conversion of Carbon Monoxide to Hydrogen and Formation of Acetate by the Anaerobic Thermophile Carboxydothermus hydrogenoformans. International Journal of Microbiology (2011). doi:10.1155/2011/641582 .

38. Guiot, S.R. and Cimpoia, R.: Potential of Wastewater-Treating Anaerobic Granules for Biomethanation of Synthesis Gas. Environ Sci Technol, 45, 2006-2012 (2011).

39. Sipma, J., Lettinga, G., Stams, A.J.M., and Lens, P.N.L.: Hydrogenogenic CO conversion in a moderately thermophilic $\left(55^{\circ} \mathrm{C}\right)$ sulfate-fed gas lift reactor: Competition for $\mathrm{CO}$-derived $\mathrm{H}_{2}$. Biotechnol Prog, 22, 1327-1334 (2006).

40. Liu, R., Hao, X., and Wei, J.: Function of homoacetogenesis on the heterotrophic methane production with exogenous $\mathrm{H}_{2} / \mathrm{CO}_{2}$ involved. Chem Eng J, 284, 1196-1203 (2015).

41. Diekert, G. and Ritter, M.: Carbon monoxide fixation into the carboxyl group of acetate during growth of Acetobacterium woodii on $\mathrm{H}_{2}$ and $\mathrm{CO}_{2}$. 17, 299-302 (1983).

42. Nguyen, N., Warnow, T., Pop, M., and White, B.: A perspective on 16S rRNA operational taxonomic unit clustering using sequence similarity. npj Biofilms Microbiomes, 2, (2016).

43. Patel, G.B., Roth, L.A., Van den Berg, L., and Clark, D.S.: Characterization of a strain of Methanospirillurn hungatii. Can J Microbial, 22, 1404-1410 (1976).

44. Genthner, B.R.S., Friedman, S. D., and Devereux, R.: Reclassification of Desulfovibrio desulfuricans Nomay 4 as Desulfomicrobium nowegicum comb . nov . and Confirmation of Desulfomicrobium escambiense ( corrig ., Formerly "escambium") as a New Species in the Genus Desulfomicrobium. Int J Syst Bacteriol, 47, 889-892 
(1997).

45. Fournier, G.P. and Gogarten, J.P.: Evolution of Acetoclastic Methanogenesis in Methanosarcina via Horizontal Gene Transfer from Cellulolytic Clostridia. J Bacteriol, 190, 1124-1127 (2008).

46. Cord-ruwisch, R. and Lovley, D.R.: Growth of Geobacter sulfurreducens with Acetate in Syntrophic Cooperation with Hydrogen-Oxidizing Anaerobic Partners. Appl Environ Microbiol, 64, 2232-2236 (1998).

47. Hamdi, O. et al.: Aminobacterium thunnarium sp. nov., a mesophilic, amino acid-degrading bacterium isolated from an anaerobic sludge digester, pertaining to the phylum Synergistetes. Int J Syst Evol Microbiol, 65, 609-614 (2015).

48. Sokolova, T.G., Kostrikina, N.A., Chernyh, N.A., Kolganova, T.V, Tourova, T.P., and Bonch-osmolovskaya, E.A.: Thermincola carboxydiphila gen. nov., sp. nov., a novel anaerobic, carboxydotrophic, hydrogenogenic bacterium from a hot spring of the Lake Baikal area. Int J Syst Evol Microbiol, 55, 2069-2073 (2005).

49. Shiratori, H. et al.: Lutispora thermophila gen. nov., sp. nov., a thermophilic, spore-forming bacterium isolated from a thermophilic methanogenic bioreactor digesting municipal solid wastes. Int J Syst Evol Microbiol, 58, 964969 (2008).

50. Kotsyurbenko, O.R., Glagolev, M.V., Nozhevnikova, A.N., and Conrad, R.: Competition between homoacetogenic bacteria and methanogenic archaea for hydrogen at low temperature. FEMS Microbiol Ecol, 38, 153-159 (2001).

51. Savage, M.D., Wu, Z., Daniel, S.L., Lundie, L.L., and Drake, H.L.: Carbon monoxide dependent chemolithotrophic growth of Clostridiurn thermoautotrophicum. Appl Environ Microbiol, 53, 1902-1906 (1987).

52. Kerby, R.L., Ludden, P.W., and Roberts, G.P.: Carbon monoxide-dependent growth of Rhodospirillum rubrum. J Bacteriol, 177, 2241-2244 (1995).

53. Slepova, T.V. et al.: Carboxydocella sporoproducens sp. nov., a novel anaerobic $\mathrm{CO}_{-\mathrm{utilizing} / \mathrm{H}_{2}-\mathrm{producing}}$ thermophilic bacterium from a Kamchatka hot spring. Int J Syst Evol Microbiol, 56, 797-800 (2006).

54. Wang, W., Xie, L., Luo, G., Zhou, Q., and Angelidaki, I.: Performance and microbial community analysis of the anaerobic reactor with coke oven gas biomethanation and in situ biogas upgrading. Bioresour Technol, 146, 234239 (2013).

55. Westermann, P., Ahring, B.K., and Mah, R.A.: Threshold Acetate Concentrations for Acetate Catabolism by Aceticlastic Methanogenic Bacteria. 55, 514-515 (1989). 